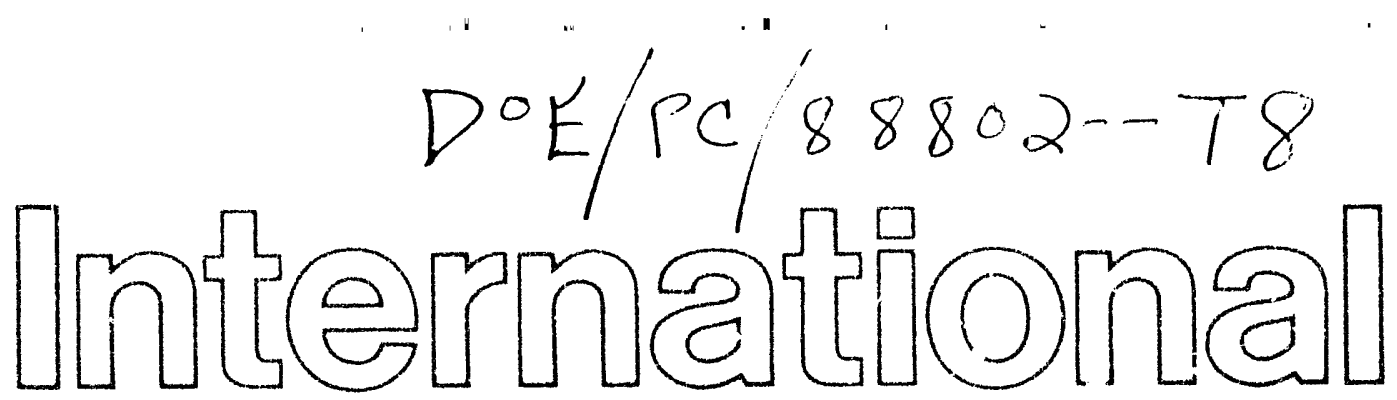

Final Report - 5 September 1991

\title{
EXPLORATORY COPROCESSING RESEARCH
}

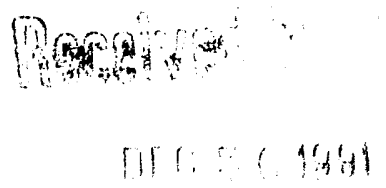

\author{
By: Albert S. Hirs thon, Doris S. Tse, Ripudaman Malhotra, Donald F. McMilleri, \\ and David S. Ross
}

SRI Project 6628

For the Period September 1988 to June 1991

Prepared for:

U.S. Department of Energy

Pittsburgh Energy Technology Center

U.S. DCIE:PETC

F.1). Box 10940

Fiitsburgh, PA 15236

Work Performed For PETC Under Contrac ${ }^{+}$ivo. DE-AC22-88PC88802

Approved:

David M. Golden

Vice President

Physical Sciences Division

\section{DISCLAIMER}

This report was prepared as an account of work sponsored by an agency of the United States Government. Neither the United States Government nor any agency thereof, nor any of their employees, makes any warranty, express or implied, or assumes any legal liability or responsibility for the accuracy, completeness, or usefulness of any information, apparatus, product, or process disclosed, or represents that its use would not infringe privately owned rights. Reference herein to any specific commercial product, process, or service by trade name, trademark, manufacturer, or otherwise does not necessarily constitute or imply its endorsement, recommendation, or favoring by the United States Government or any agency thereof. The views and opinions of authors expressed herein do not necessarily state or reflect those of the United States Government or any agency thereof. 


\section{DISCLAIMER}

This report was prepared as an account of work sponsored by the United States Govemment. Neither the United States nor the United States Department of Energy, nor any of their smployess, makes any warranty, express or implied, or assumes any legal liability or responsibility for the accuracy, completeness, or usetulness of any information. apparatus, proctuct of process disclosed or represents that its use would not infringe privately owned rights. Roterence herein to any specific commercial proctuct, process, or service by trade name, mark, manufecturer, or othenwise, does not necessarily constitute or imply its endorsement, recommendation, or tavoring by the United States Govemment or any agency thereof. The views and opinions of authors expressed herein do not necessarily stete or reflect those of the United States Government or any agency thereof.

\section{PATENT STATUS}

This wnical report is being tranemitud in advance of DOE patent clearance and no further dissemination or publication shall be made of the report without prior approval of the DOE Pateist Counsel.

\section{TECHNICAL STATUS}

This thrical report is being tranemitted in advance of DOE review and no further discemination or publication shall be made of the report without prior approval of the DOE Project/Program Alenager. 


\section{SUMMARY}

This final report summarizes our research on Contract No. DE-AC22-88PC88802, "Exploratory Coprocessing Research." The objectives of this project were to (1) study the scope of the beneficial effects of hydrothermal pretreatment of coal on subsequent conversion, (2) identify and study the chemical or physical causes of this effect, and (3) attempt to elucidate the chemistry responsible for any coal-resid synergisms. This project was divided into the three tasks summarized below. In addition, we have included several manuscripts in Appendices A through E, which elaborate on our research.

\section{TASK 1: SCOPE OF HYDROTHERMAL PRETREATMENT}

In past work at SRI, significant enhancements of conversion were observed from hydrothermal pretreatment of an Illinois \# 6 coal for conversion in CO/water systems. The purpose of this task was to determine the generality of this effect with respect to coal type and its applicability to coprocessing technology. Three types of coals were investigated from the Argonne coal bank as well as one Illinois \#6 coal from the Penn State coal bank (PSOC 1098). The coprocessing tests following the various pretreatments were conducted by using Maya atmospheric tower bottom (ATB) at $425^{\circ} \mathrm{C}$ and $1200 \mathrm{psig}$ of hydrogen, in the absence of any added catalyst. Both $300-\mathrm{mL}$ autoclaves and 43-mL microreactors were used and found to give similar trends for the different coal ranks. The Wyodak subbituminous coal had the greatest pretreatment effect during coprocessing, with lignite giving a moderate effect and both the PSOC Ilinois \#6 coal and the Argonne Illinois \#6 coal giving no observable effect.

Wyodak was used to determine the "optimal" pretreatment method, since it showed the greatest effect of pretreatment. The optimal hydrothermal pretreatment temperature was found to be in range of 300 to $350^{\circ} \mathrm{C}$. Several other methods of pretreatment were also investigated for comparison; these pretreatments included dry thermal pretreatment, thermal soak in tetralin and acetone acid wash. The use of acid was prompted by the interesting results of Miller et al., who reported an increase the reactivity of low rank coals by pretreatment with acidic methanol. We wanted to see if this effect might be due to the effect of acid, or water removal, or alkylation. The thermal treatment was used as a baseline case for the other pretreatments, and the tetralin 
pretreatment is an example of pretreating with a potential liquefaction solvent. The results showed that the aqueous pretreatment techniques gave the best overall conversions.

\section{TASK 2: CHEMISTRY OF PRETREATMENT}

The purpose of this task was to determine the factors responsible for any benefits observed from aqueous thermal pretreatment and how these factors may relate to coal liquefaction in general. Examination of the pretreated coal showed very distinct differences after pretreatment, such as a loss of oxygen and increases in reactivity of the coals toward volatiles release as determined by pyrolysis in the inlet of a field ionization mass spectrometer (FIMS). We suggest that the effect of the water is to release these volatiles from the mineral/organic interface of the coal and thus prevent them from undergoing retrogressive reactions.

The various potential roles of oxygen, especially of phenolics, in liquefaction have been widely discussed by many workers, including those at SRI. In this task we used model phenols to explore the effect of clays on the polymerization of reactive phenolic structures in coal and the effect of water in controlling this polymerization. Over a range of temperatures from $300^{\circ}$ to $400^{\circ} \mathrm{C}$, the presence of water substantially reduced the loss of phenolic probe molecules, sometimes from $90 \%$ loss (i.e., polymerization) to less than $10 \%$ loss. Thus, the results from this study are consistent with the suggestions above that a major role of water is to prevent the retrogressive reactions of phenolic materials in coal. To help determine the role of water in this retrograde chemistry, we added liseled 180 water in the presence of clay and phenol. The $18 \mathrm{O}$ was found to incorporate into the phenol, both with and without kaolin present. We know of no precedent for such an exchange and suggest that the water must be involved in reversing an intermediate during the polymerization of the phenol.

\section{TASK 3: CHEMISTRY OF SYNERGY}

When coals and resids are processed together, there are certain physical and chemical interactions that may be beneficial or harmful to net conversion. For coprocessing to be a useful coal liquefaction alternative, it is clearly desirable to maximize beneficial interactions and minimize harmful ones. In previous work we have suggested that increased aromaticity of the reaction medium resulting from the presence of the coal may be beneficial (to the conversion of the coal and/or limitation of resid coking) because the polycyclic aromatic hydrocarbons are better $\mathrm{H}$-shuttlers and can better use hydrogen from molecular $\mathrm{H}_{2}$, or even from aliphatic structures of 
the resid, for inducing cleavage of strong bonds. This conclusion was also borne out by a mechanistic numerical model.

To explore this factor further and to resolve recent controversy about the generality and mechanism of $\mathrm{H}$-transfer induced bond cleavage, we studied the dealkylation of several benzyl aromatics in mixtures of anthracene and dihydroanthracene. In accord with the predictions of our model, the experimentally determined rate constants correlated with the exothermicity of $\mathrm{H}$ addition. Together with recent results from other laboratories, these results support the suggestion that part of beneficial interactions between coal and resid do lie in the types and accessibility of the hydroaromatic species present in the resid or recycle solvent.

\section{CONCLUSIONS}

The principal findings of this project can be summarized in the following four statements.

- Hydrothermal pretreatment of low rank coals with liquid water leads to enhanced conversions even under coprocessing. This pretreatment has minimal impact on the conversion of medium rank coals like Illinois \#6.

- For the Wyodak coal, maximum benefit is realized for pretreatments in the $300^{\circ}$ $350^{\circ} \mathrm{C}$ range.

- Dry thermal pretreatment is definitely detrimental for subsequent conversions, and even a thermal soak in a donor solvent like tetralin is not as beneficial as hydrothermal pretreatment.

- Clay-catalyzed coupling of phenols is efficiently mitigated by the presence of water. In preventing these coupling reactions, water acts not merely by modifying the surface acidity of clays, but, as shown by studies with $18 \mathrm{O}$ labeled water, by chemically intercepting an intermediate along the path to the ultimate coupling product, dibenzofuran. This chemistry may be responsible for the beneficial impact of hydrothermal pretreatment. 


\section{CONTENTS}

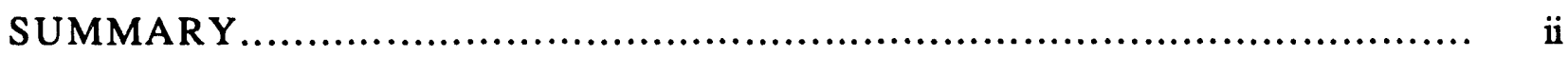

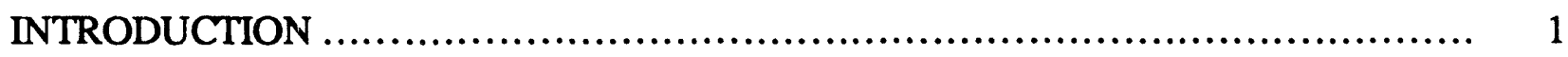

TASK 1: SCOPE OF HYDROTHERMAL PRETREATMENT ........................ 3

Experimental ............................................................................ 3

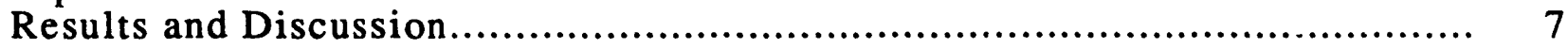

TASK 2: CHEMISTRY OF PRETREATMENT ................................ 15

Background ......................................................................... 15

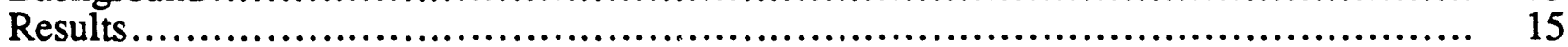

TASK 3: CHEMISTRY OF SYNERGY ...................................... 22

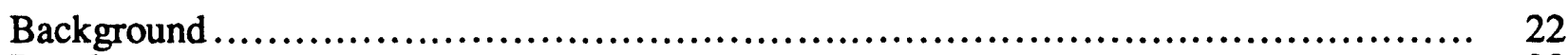

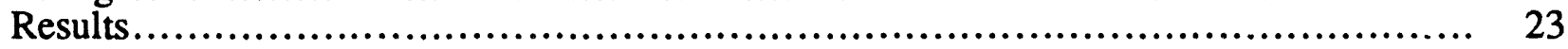

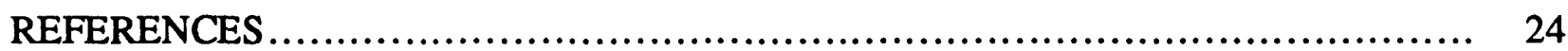

\section{APPENDICES}

A HYDROTHERMAL PRETREATMENT EFFECTS ON CO-PROCESSING.......... A-1

B WEAK LINKS AND INTERFACIAL CHEMISTRY IN COAL ................... B-1

C THE EFFECTS OF HYDROTHERMAL TREATMENT ON WYODAK COAL.... C-1

D EFrECT OF HYDROTHERMAL PRETREATMENT FOR COPROCESSING...... D-1

E CLEAVAGE OF BENZYLAROMATICS AND THEIR RELEVANCE TO COAL CONVERSION ........................................................ E-1 


\section{INTRODUCTION}

Recent studies show that mild hydrothermal treatment of an Ilinois \#6 coal substantially enhances conversion into soluble products. For instance, the convertibility of an Illinois \#6 coal into toluene-soluble products increased from 35\% to almost 70\% when the coal was treated for 30 minutes with water at $250^{\circ} \mathrm{C}$ under nitrogen, and then subjected to conversion in $\mathrm{CO} /$ water systems. ${ }^{1}$ Similar favorable effects of mild hydrothermal pretreatment have been reported for conversions in pyrene ${ }^{2}$ and for rapid hydropyrolysis. ${ }^{3-4}$ However, pretreatment of coals with water has not always been beneficial and added water (or un-removed indigenous water) can even be detrimental. ${ }^{2,5}$ Furthermore, since there are certain processing disadvantages (e.g., the energy cost of water removal, the lowering of $\mathrm{H}_{2}$ partial pressure, and forniction of emulsions) that accompany the addition of water, a substantial benefit in conversion from aqueous pretreatment may be necessary for it to represent a practical processing option.

The principal objective of this project was to determine whether the beneficial effects of mild hydrothermal pretreatment could be exploited in the context of coprocessing. In our threetask research program, our first task was to determine the impact of hydrothermal pretreatments at various temperatures on a single coal, Wyodak, which is known to benefit from such pretreatment for conventional liquefaction, and to see if it also exhibits enhanced conversions under coprocessing. We then determined how coals of different rank respond to brief hydrothermal action. Finally, we compared the impact of hydrothermal pretreatment with other pretreatments such as thermal soak in donor solvent and low temperature drying.

In the second task, we conducted experiments designed to lead to a better understanding of the effects of water observed in Task 1 and then to expand those findings through the use of probe molecules to explore resid-coal chemistry. One focus of this task was the effect of hydrothermal contact on retrogressive reactions in coal structures, particularly phenolics.

The third task derives from earlier DOE-sponsored work in which we showed that coal liquefaction is not limited to simple thermal scission of weak bonds, but that bonds that are too strong to break thermally can also cleave as a result of hydrogen atom transfer to aromatics bearing critical linkages. This earlier research has led to a substantial revision of the picture for coal liquefaction: the solvent should now be perceived as an active reagent bringing about a substantial portion of the necessary bond cleavage. Accordingly, we have applied this view of coal 
liquefaction to coprocessing by examining the various observed synergies (or lack thereof) that have been reported in the literature. 


\section{TASK 1: SCOPE OF HYDROTHERMAL PRETREATMENT}

The objective of this task was to determine how general the beneficial effect of hydrothermal pretreatment is regarding the coal type (e.g., rank, mineral and moisture content) and the conditions of the subsequent conversion, and how it compares with other forms of pretreatment. The effect was evaluated in terms of yield into hexane-soluble material and heteroatom content. In addition, comparisons were made between microautoclaves and larger autoclaves. Much of this work is presented in several manuscripts, which are attached as Appendices A through E.

\section{EXPERIMENTAL}

The coals used in this study were a PSCC 1098 Illinois \#6 coal, a Wyodak-Anderson seam subbituminous coal, Illinois \#6 seam high volatile bituminous coal, and Beulah-Zap seam North Dakota lignite; the latter three coals were obtained from the Argonne premium coal bank and used as received. The PSOC coal was ground to 60-200 mesh under nitrogen and dried under vacuum at $76^{\circ} \mathrm{C}$ for 6 hours and stored under nitrogen. The resid used for these experiments was a Maya ATB obtained from Pittsburgh Energy Technology Center.

\section{Reactors}

The reactor systems used were either a $300-\mathrm{mL}$ stirred reactor made by Autoclave Engineers or a 43-mL shaking microautoclave built for this project. The construction of the microreactor was based in part on reactors described by Maa et al. at Exxon 6 and by Winschel et al. at Consolidation Coal (Consol), ${ }^{7}$ combining elements of both designs to suit our present purposes. Thus, like the Consol design, our reactor is constructed from 1-in. OD, 0.688-in. ID, 316 stainless steel tubing $51 / 2 \mathrm{in}$. long fitted with a Swagelok SS-1610-1-16W pipe weld connector on one end (Figure 1a). The other end is welded shut with a stainless steel plate. The reactor is sealed shut by with a Swagelok SS-1610-P cap after filling with the desired reactants. This arrangement has the advantage that seal is made and remade on a ferrule that is part of a machined end cap, rather than on a ferrule crimped onto the steel tubing.

This reactor was then suspended in a manner similar to the Exxon design. A 4-in. long 1/4-in.-OD, 1/8-in.-ID stainless steel tube is welded on the side of the reactor near the balance 
point. The tube was extended an additional 12 in with an 1/8-in.-OD 0.069-in.-ID stainless steel tube, which was then fitted to an Autoclave Engineers (AE) high pressure valve using the $\mathrm{AE}$ fittings.

A holder was fashioned as shown in Figure 1b, fitting onto a Makita model JR3000V variable speed reciprocating saw. The maximum speed of the saw is $2300 \mathrm{cpm}$, with a $5 / 8$-in. stroke. The saw was secured by use of Unistrut braces about an Omega model FSB-4 sandbath. The speed of the saw is controlled by a variable transformer. An overall view of the reactor system is shown in Figure 1(c).

\section{Reaction Conditions}

Pretreatment and Coprocessing. The pretreatment prosedure for the $300-\mathrm{mL}$ reactor is as follows. The coal was pretreated by placing approximately $5 \mathrm{~g}$ of coal and $10 \mathrm{~mL}$ of distilled water in a $50-\mathrm{mL}$ bomb with a glass insert. The reactor was purged and pressurized with $500 \mathrm{psi}$ of nitrogen and inserted into a sandbath for $30 \mathrm{~min}$ at the desired pretreatment temperature. After the reactor had cooled and the insert was removed, the coal was transferred into a centrifuge tube. The aqueous layer was removed with a pipet after centrifuging the mixture, and the pretreated coal was washed twice with distilled. water. The wet coal and Maya ATB were then transferred to the reactor, and the coprocessing experiment was conducted under the conditions described above.

The 43-mL microreactor experiments were conducted in a similar manner, only on a smaller scale. The advantage of these microreactors is that, because they have a faster heat-up time we can better assess temperature effects. The reactors were charged with $2.25 \mathrm{~g}$ of Argonne Wyodak coal and $4.5 \mathrm{~g}$ of Maya and filled with $1200 \mathrm{psig}$ of hydrogen (cold). The reactor was then shaken $(\sim 500 \mathrm{cpm})$ at $425 \mathrm{C}$ for 1 hour in a fluidized sandbath. Before the reactor was opened, it was cooled in dry ice to prevent volatiles from escaping. For experiments in which the coal was pretreated thermally with water, the reactor was charged with $2.25 \mathrm{~g}$ of coal, $10 \mathrm{~mL}$ of water, and 500 psig of nitrogen. The mixture was then heated and agitated in the sandbath for 30 minutes at the desired temperature. The reactor was cooled in sand, carefully opened, and the excess water removed by pipette. Coal that was inadvertently removed along with the water was weighed to determine the actual amount used in the next set. The appropriate amount of Maya ATB was then added to the reactor, which was then charged with 1200 psig of hydrogen and heated as described above. Following the reaction, the contents of the reactor were filtered through a Teflon $0.45 \mu \mathrm{m}$ membrane filter with the help of excess hexane. The residue was dried and weighed to obtain the yield of the hexane-insolubles, which was the principal diagnostic used in 


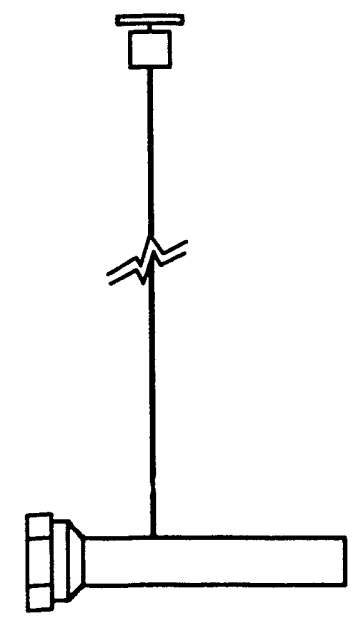

(a)

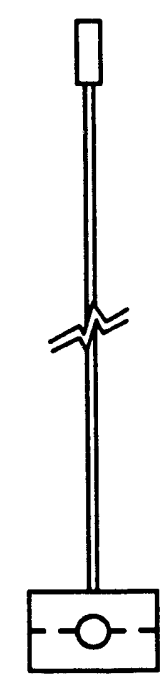

(b)

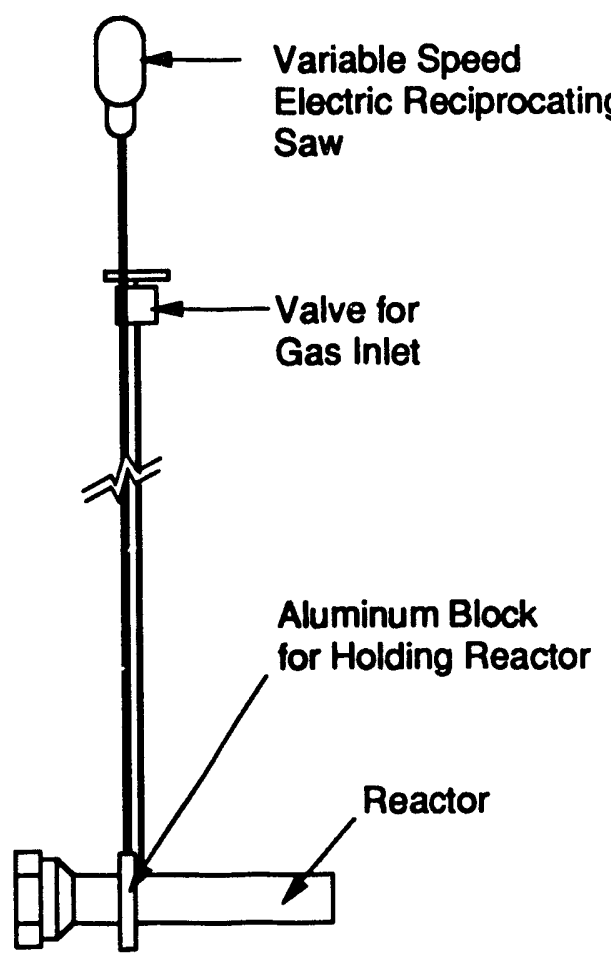

(c)

RAM-6628-22

Figure 1. Microautoclave reactor system.

(a) reactor; (b) holder for reactor;

(c) reactor attached to shaker. 
this study, although other diagnostics such as THF-solubles, elemental analyses, and FIMS volatilities were also used. In some cases the hexane was removed under low pressure and the yield of hexane-solubles was also directly measured.

These reaction conditions were based on those of Cugini et al. ${ }^{8}$, who used coprocessing conditions of $1200 \mathrm{psi}$ hydrogen and $425^{\circ} \mathrm{C}$ for 1 hour. Several ranges of resid to coal were used, with the majority of experiments using 1 part coal to either 2 parts or 3 parts of resid. All operations were conducted either in a nitrogen-filled glove bag or under a blanket of nitrogen, although brief exposure of the pretreated coal to air during the transfer could not be avoided. A few coprocessing experiments were also conducted in the presence of an iron catalyst to see if any beneficial impact of hydrothermal pretreatment was also realized for catalytic conversions.

Although the ultimate value of any pretreatment step will be determined by the incremental impact of the pretreatment for subsequent catalytic coprocessing under the high severity conditions relevant to actual process operation, we chose to limit most of the conversion tests to thermal conditions. The main reason for this choice was that it is difficult to mimic bench-scale catalytic runs in miccoautoclaves. For example, researchers at Consol have found that addition of catalyst in their microautoclaves was detrimental. ${ }^{9}$ Researchers at Hydrocarbon Research, Inc. (HRI), have reported that, in order to have their batch microautoclave experiments successfully mimic their continuous flow ebulated bed reactor conversions, they had to charge the microautoclaves with a 3:1 mixture of a coal liquefaction recycle solvent and the resid as the simulant for the reaction medium provided by the natural "internal recycle" of a backmixed reactor. 10 Since one of the interpretations of the need for a charge that has three times as much recycle solvent as resid is that the full benefits of catalyst are not achieved with a poor solvent, we felt it best for the time being to define the benefits of pretreatment in a thermal system similar to that used by Cugini and coworkers. 8

Probe Molecule Studies. All reactions using probe molecules were conducted in fused silica tubes sealed under vacuum and heated in pressure jackets in a molten salt bath whose temperature was controlled to within $\pm 1^{\circ} \mathrm{C}$. The reaction mixtures were analyzed by GC-MS and where appropriate by FIMS. 


\section{RESULTS AND DISCUSSION}

\section{Effect of Pretreatment Temperature}

Coprocessing experiments using PSOC 1098 Ilinois \#6 coal and Argonne Illinois \#6 and Wyodak coals were run both in $300-\mathrm{mL}$ autoclaves and in $43-\mathrm{mL}$ microautoclaves using coprocessing conditions of $1200 \mathrm{psi}$ hydrogen and $425^{\circ} \mathrm{C}$ for 1 hour, conditions similar to those of Cugini et al..$^{8}$ Because the $300-\mathrm{mL}$ autoclaves had slow heat-up times, we decided to use smaller microreactors for these conversions; we conducted the majority of research using these smaller reactors. Both reactors showed that Wyodak coal was more susceptible to pretreatment. Thesefore, this coal was used for exploration of the pretreatment conditions. Experiments were conducted using pretreatments at $250^{\circ}, 300^{\circ}$, and at $350^{\circ} \mathrm{C}$, followed by coprocessing with a ratio of 1 part coal and 2 parts Maya ATB and 1200 psig of hydrogen at $425^{\circ} \mathrm{C}$. In each case the pretreatment increased the conversion to hexane-soluble material. Results obtained with microautoclaves paralleled those with the larger autoclave. As shown in Figure 2, lower amounts of hexane-insolubles were formed from pretreated coals than from a.s-received coals. Furthermore, pretreatment at $300^{\circ} \mathrm{C}$ was more beneficial than at $250^{\circ} \mathrm{C}$, although further increase in the pretreatment temperature to $350^{\circ} \mathrm{C}$ provided minimal additional benefil.

\section{Effect of Coal Type}

The pretreatment conditions found to be optimum for Wyodak coal were used to evaluate the other coals to determine the generality of the effect. Table 1 presents data from the coprocessing studies with Argonne premium samples of Wyodak, Illinois \#6, and North Dakota coals and lignite. The first entry in Table 1 represents baseline values (conversions of Maya alone with no coal added). Using the conversion of Maya alone, we can calculate the conversion of coal, assuming there is no interaction between the coal and resid; i.e., that the \% resid converted to hexane-insolubles is unaffected by the coal. We have included these derived coal conversion values in Table 1 only because other studies have often quoted "coal conversion" values. However, since we know the assumption needed to arrive at these values to be invalid, we have chosen to discuss the results simply in '-rms of the overall yields of hexane-insolubles (as a rough measure of the nondistillables). 


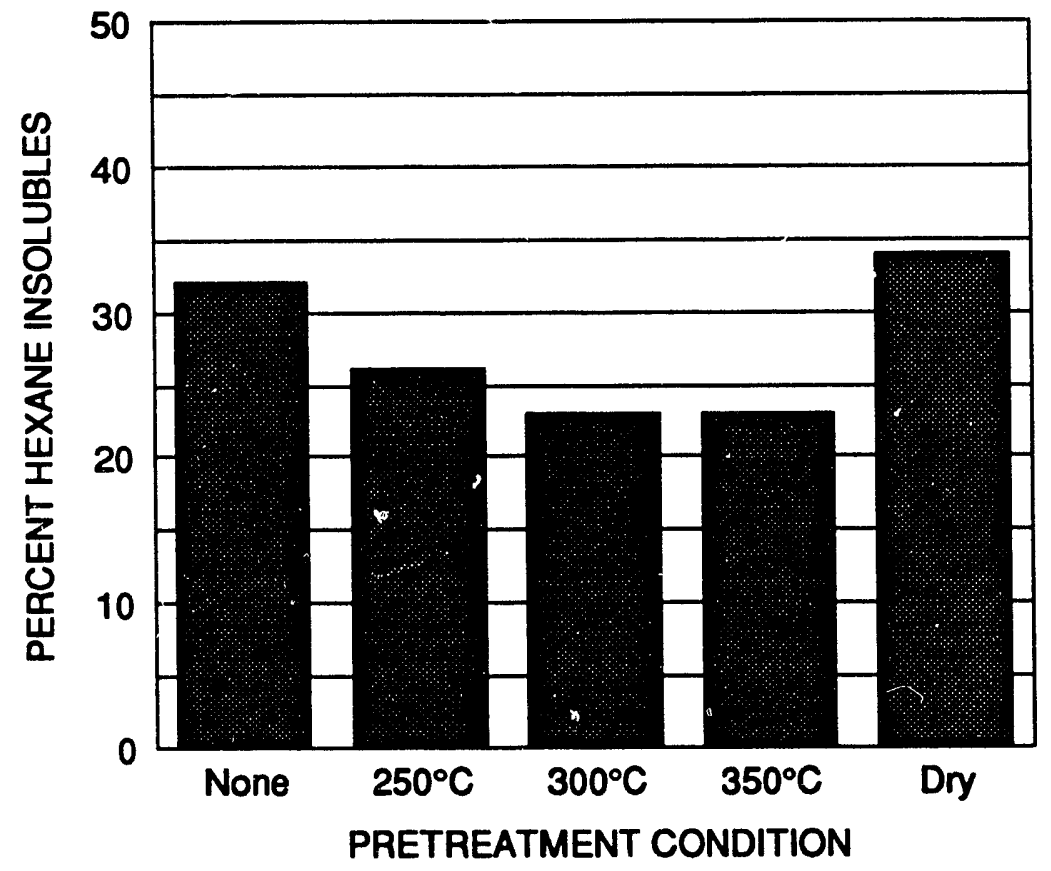

RM-6628-23

Figure 2. Effect of pretreatment temperatures. 
As shown in Table 1, ...e yield of hexane-insolubles ranged from $22 \%-35 \%$ and indicates that a significant portion of the coal has been converted to hexane-solubles. Although bituminous coals are generally more easily converted (to THF-solubles) than subbituminous coals, these

Table 1

THE EFFECTS OF PRETREATMENT ON COPROCESSING COALS OF DIFFERENT RANK WITH MAYA ATB IN A MICROAUTOCLAVE a

Entry No.

Coal

Pretreatment

$\left({ }^{\circ} \mathrm{C}\right)$

Hexane Insoluble $(\%)$ Conversionb $(\%)$

\begin{tabular}{lllll}
1 & None & None & 18 & - \\
2 & Wyodak & None & 32 & 40 \\
3 & Wyodak & $350^{\circ}$ & 22 & 69 \\
4 & Wyodak & $350^{\circ}$ & 25 & 61 \\
5 & Illinois \#6 & None & 34 & 33 \\
6 & Illinois \#6 & $350^{\circ}$ & 35 & 30 \\
7 & Lignite & None & 28 & 52 \\
8 & Lignite & $350^{\circ}$ & 24 & 64 \\
\hline
\end{tabular}

aReactions of coal and Maya ATB at $425^{\circ} \mathrm{C}$ for $1 \mathrm{~h}$ at and $1200 \mathrm{psi} \mathrm{H}_{2}$.

bCoal conversion calculated assuming that the insoluble material from the Maya remains the same during the coprocessing experiment.

$\%$ Conversion $=100-[(H)-12) /(33)] \times 100$

data show the Wyodak and Illinois \#6 coals that were not pretreated converted to hexane-solubles to about the same extent, with overall yields of $32 \%-34 \%$ hexane-insoluble material. The pretreatment of Wyodak gave a significant enhancement of conversion, no benefit for the Illinois \#6 coal, and a moderate benefit for the lignite. Although we had optimized the pretreatment conditions using the Wyodak coal, we have no reason to assume that these conditions are optimal for other coals as well. The lignite might show a more pronounced effect with a lower temperature hydrothermal pretreatment. However, exploration of optimal conditions for all coals was beyond the scope of the present work. Nevertheless, these results show that the beneficial effects of hydrothermal pretreatment are not limited to the Wyodak coal and that other low rank coals also show qualitatively similar enhancements in conversion. 
Since low rank coals such as the Wyodak and lignite have a relatively higher proportion of phenolics and carboxylates than the higher ranking Illinois \#6 coal, we would predict that these lower rank coals would have the most benefit from the aqueous pretreatment. Thus our work is consistent with this prediction and indicates the generality of the pretreatment effect among lowrank coals. However, the mere presence of some water vapor during conversion is evidently not sufficient to see the benefits observed here for pretreatment, since both the Wyodak and lignite already have high moisture contents (ca. 30\%) and are not dried before coprocessing in our baseline conversion tests. Thus, we only see the benefit when the amount of water and the pretreatment temperature are such that the coal is in a liquid water medium during pretreatment.

The larger effect of the pretreatment on the Wyodak coal compared with the lignite was not anticipated. The association of the pretreatment benefits with mitigation of retrograde reactions of oxygen functional groups had led us to the natural expectation that, if the impact was larger with the subbituminous coal than with the bituminous coal, it would be still larger with the slightly higher oxygen content lignite (MAF oxygen: 20.3 vs $18.0 \mathrm{wt} \%$ ). Most of our work on pretreatment was with the Wyodak coal, and perhaps some pretreatmient conditions that are not optimum for Wyodak would give a larger enhancement of the lignite conversion. The relative amounts of the different oxygen functionalities in these coals, as well as the nature of the clusters to which they are attached are not exactly the same. The most obvious differences are that the lignite has a higher proportion of its oxygen as carboxylic acid and a smaller proportion of its phenolic $\mathrm{OH}$ is methylated, than in the Wyodak. Thus a thorough study of the chemical effect of the pretreatment on different types of functionalities present in coals of varying ranks is needed to more fully understand the nature of the effects and to predict optimal processing conditions.

\section{Alternative Methods of Pretreatment}

We investigated and compared several known methods of pretreatment under coprocessing conditions. Since Wyodak coal was shown to be more susceptible to pretreatment, this coal was used for these comparisons, using pretreatments at $350^{\circ} \mathrm{C}$. The coprocessing itself was again with a ratio of 1 part coal and 2 parts Maya ATB, 1200 psig (cold) hydrogen pressure, and reaction temperature $425^{\circ} \mathrm{C}$. The alternative pretreatment methods included acidic acetone, thermal, hydrothermal, tetralin, and dispersed iron catalyst loading. The results are presented in Table 2. 
Table 2

THE EFFECTS OF CHANGING PRETREATMENT CONDITIONS ON COPROCESSING OF WYODAK COAL WITH MAYA ATB a

\begin{tabular}{|c|c|c|c|}
\hline Entr; No. & Pretreatmenta & $\begin{array}{c}\text { Hexane Insolubles } \\
\text { (wt\%) }\end{array}$ & Coal Conversion b \\
\hline 1 & Maya (no coal) & 18 & - \\
\hline 2 & Maya (no coal, $350^{\circ} \mathrm{C}$ ) & 20 & - \\
\hline 3 & Maya (no coal, $350^{\circ} \mathrm{C}$ ) & 23 & - \\
\hline 4 & None & 32 & 40 \\
\hline 5 & $350^{\circ} \mathrm{C}$ & 22 & 69 \\
\hline 6 & $350^{\circ} \mathrm{C}$ & 25 & 60 \\
\hline 7 & Thermal $350^{\circ} \mathrm{C}$ & 34 & 33 \\
\hline 8 & Thermal $350^{\circ} \mathrm{C}$ & 34 & 33 \\
\hline 9 & Vacuum dried $56^{\circ} \mathrm{C}$ & 34 & 33 \\
\hline 10 & Acetone dried & 33 & 36 \\
\hline 11 & Tetralin $350^{\circ} \mathrm{C}$ & 28 & 52 \\
\hline 12 & Tetralin $350^{\circ} \mathrm{C}$ & 27 & 55 \\
\hline 13 & Iron(II) sulfate & 27 & 55 \\
\hline 14 & Iron(II) sulfate & 29 & 49 \\
\hline
\end{tabular}

aReactions of coal and Maya ATB at $425^{\circ} \mathrm{C}$ for $1 \mathrm{~h}$ at 1200 psi $\mathrm{H}_{2}$ except for experiment 2, which was conducted under $\mathrm{N}_{2}$.

bCoal conversion calculated assuming that the insoluble material from the Maya remains the same during the coprocessing experiment.

Hydrothermal Pretreatment of Oil. As in Table 1, the first entry gives the yield of the hexane-insolubles that results from processing Maya ATB alone. Entries 2 and 3 give the yield of hexane-insolubles when the oil is subjected to a hydrothermal pretreatment followed by processing. These experiments were conducted to ensure that the effect of water in pretreatment was unique to the coal. Maya ATB was pretreated with water at $350^{\circ} \mathrm{C}$, the water was removed, and the pretreated Maya was then heated at $425^{\circ} \mathrm{C}$ for $1 \mathrm{~h}$ under either $\mathrm{N}_{2}$ (entry 2) or under $\mathrm{H}_{2}$ (entry 3). In neither case was the hexane-insoluble yield any lower than the case without pretreatment. The fact that the yield of hexane-insolubles una $: x$ nitrogen and hydrogen are similar for pure Maya and suggests that the thermal conversion of Maya to hexane-solubles is primarily a 
disproportionation reaction, where the hydrogen used for the portion that is "upgraded" comes directly from some other portion of the Maya. This observation is consistent with the use of hexane-insolubles as a rough measure of nondistillable product and with literature studies on resid upgrading, which show the distillate yield to be roughly independent of catalyst, $\mathrm{H}_{2}$, and medium, but show the THF-insolubles (or "coke" yields) to be critically dependent on these factors. $11,12,13$ In chemical terms, the aliphatic portions of the resid (particularly the paraffins and paraffinic side chains) cleave readily under simple thermal stress via the well known $\mathrm{H}$-atom abstraction- $\beta$ scission sequence as established by the work of Rice, Hertzfeld, and Kossiakoff. 14 If most of the readily derivable distillate comes from this portion of the resid, the main requirement for its production is heating aione; the yield of THF-insolubles, or coke, depends mainly on whether the hydrogen needed to satisfy stoichiometric requirements of the paraffin fragmentation comes from an external source or is "extracted" from coke intermediates.

Dry Thermal Pretreatment. To determine if the beneficial effect of the pretreatment was not simply due to heating the coal to $350^{\circ} \mathrm{C}$, we heated dry coal to $350^{\circ} \mathrm{C}$, and subjected it to coprocessing at $425^{\circ} \mathrm{C}$. As given in entries 7 and 8 (duplicate experiments), dry thermal treatment resulted in substantially greater yields of hexane-insolubles than hydrothermal pretreatment (entries 5 and 6) and even slightly greater than no pretreatment (entry 4).

Mild Alkylation - Solvent-Drying. Miller et al. have shown some interesting results involving pretreatment with acidic alcohol solution. ${ }^{15}$ The premise of their work was that alkylation prevents the phenolic and carboxylate groups from undergoing retrogressive reactions and that treatment with acidic alcohol solutions might represent a simple and inexpensive way to partially alkylate low rank coals. However, alkylations are not generally achieved with aqueous acids, and the actual cause of the ohserved beneficial may be the dewaiering and/or ion-exchange that accompanies this pretreatment. The removal of water under mild conditions, such as under vacuum or by solvent drying, enhances conversions more than water removal under more severe conditions (i.e., higher temperature, and possibly in the presence of small amounts of oxygen). ${ }^{16}$ To test whether it was removal of water under mild conditions that was responsible for the effect observed by Miller et al. ${ }^{15}$, we used anhydrous acetone, which is also completely miscible with water but cannot alkylate hydroxyls. However, as shown in Table 2 (entry 10), this treatment led to a hexane-insolubles yield of only $33 \%$, compared with the baseline case of $32 \%$. Similarly, vacuum dried coal gave a hexane-insolubles yield of $34 \%$, not significantly different from the base case. Hence, we believe that the effect of pretreatment with acidic methanol is due to small 
amounts of alkylation as postulated by Miller or more likely due to ion-exchange. The latter possibility was not tested under the present contract.

Thermal Soak in a Donor Solvent. We also determined the effect of mild thermal pretreatment in a donor solvent. Previous studies at PETC ${ }^{17}$, as well as reports of beneficial effects of temperature staging in donor solvent liquefaction ${ }^{18}$, suggested that providing a moderate temperature "soak" in, say, tetralin might significantly enhance the subsequent liquefaction. This treatment might be particularly beneficial in the case of coprocessing, where the nominal liquefaction solvent, a largely aliphatic resid, is very poor compared to tetralin, which itsilf ranks as fair among donor solvents. Duplicate experiments (entries 11 and 12) demonstrate a small beneficial effect from pretreatment with tetralin, about $1 / 3$ the benefit of the aqueous pretreatment. As in the aqueous pretreatment experiments, we removed only that portion of the pretreatment solvent that could be taken off as a supernatent. Therefore, the residue of imbibed tetralin in the swollen coal might be expected to aid the subsequent liquefaction, even if the pretreatment itself had no effect.

\section{Hydrothermal Pretreatment and Catalytic Conversion}

Iron salts or oxides have often been used to enhance the conversion of low rank coals. One of the functions of the iron appears to be to help cleave or remove some of the oxygen functionalities in the coal, which are considered to cause retrogressive reactions. Low rank coals tend to have a low natural iron content. The low rank coals (Wyodak and lignite) have a pyrite content of $0.1 \%$ to $0.3 \%$, whereas the Illinois \#6 coal contains $5.5 \%$ pyrite. Thus any effect of iron should be most easily observed in the lower rank coals such as the Wyodak studied here. We conducted experiments on iron catalysis using the method of Fouda et al., who added ferrous sulfate to Forrestburg subbituminous coal for coprocessing experiments. 19

The iron was impregnated in two ways. In the first method, the coal was pretreated, iron was added in an aqueous solution, and, the coal was dried under vacuum. Maya ATB was then added, and the mixture was subjected to the normal coprocessing experiment. The effect of the combination of iron and pretreatment appeared to be minimal, giving the same conversions as without pretreatment. For the second method, the excess water was removed from the pretreated coal and then iron and the Maya were directly added. The coal was not dried before conversion.

As shown in Table 3, the addition of the iron sulfate enhanced conversion, as we had anticipated; however, we did not observe as great an enhancement as with the aqueous pretreatment. There can be several reasons for these differences in reactivity, based on how and 
when the pretreatment works. The mechanism of the aqueous pretreatment is not well understood, but we have aridience that it prevents retrogressive reactions at temperatures at least as low as $300^{\circ} \mathrm{C}$. In contrast, researchers have shown ${ }^{20}$ that the most active form of the iron is pyrrhotite; however, the iron does not transform into pyrrhotite until much higher temperatures, in the range of $400^{\circ} \mathrm{C}$. Thus the iron sulfate might not significantly inhibit retrogressive reactions at low temperatures.

\section{Table 3}

\section{EFFECT OF IRON AND HYDROTHERMAL PRETREATMENT IN COPROCESSING MAYA} ATB AND WYODAK COAL IN MICROAUTOCLAVE

\% Hexane insoluble

Pretreatment

None

Hydrothermal $350^{\circ} \mathrm{C}$
32

$-$

24
With $\mathrm{FeSO}_{4}$

$22^{b}$

a Method 1, coal dried before conversion

bMethod 2, coal not dried. 


\section{TASK 2: CHEMISTRY OF PRETREATMENT}

\section{BACKGROUND}

The goal of this task was to understand the causes for the benefits of hydrothermal pretreatment and how they relate to the ultimate convertibility of coal. Various factors could explain the beneficial effect of water. One possibility is that morphological changes affect mass transfer rates because the water contact increases pore volume and therefore opens the coal structure for subsequent conversions. However, other, more chemical, explanations must also be considered.

In this task we examined the nature of the pretreatment by studying the properties of pretreated coals and the reactions of model phenols thought to represent structures undergoing retrogressive reactions in coal. We found that the pretreatment appears to chemically and physically "loosen" the coal matrix and allow the release of volatiles. Also, using model systems, we found that hydrothermal treatment tends to minimize polymerization reactions, and we suggest that at least part of the pretreatment effect may be to minimize retrogressive reactions. Our efforts in this task are briefly described below and in Appendix D.

\section{RESULTS}

\section{Effect of Pretreatment on Coal}

The nature of pretreatment is being studied both on this program and on a second DOEsupported program (Contract No. DE-AC22-89PC89880). Included in these studies was an investigation of the physical and chemical changes in the coal itself (for Argonne Premium samples of Wyodak) following 30-min treatment in liquid water at autogenous pressures at $150^{\circ}, 250^{\circ}$, and $350^{\circ} \mathrm{C}$. The volatility patterns of the coal tars evolved were recorded using pyrolysis-field ionization mass spectrometry (py-FIMS), and in all cases the ultimate tar yields were $25 \%-30 \%$ of the starting coal on a mass basis. There were small changes following the $250^{\circ}$ pretreatment, but major effects were seen in the $350^{\circ}$ work. The total weight loss remained essentially unchanged, but the tars were released at a lower temperature. The pretreatment essentially liberated large tar 
molecules that would otherwise have been pyrolyzed to smaller molec ules before being released into the vapor phase during the analysis.

Figure 3 presents first the individual FI-mass spectra for the as-received and pretreated Wyodak coal and then a difference spectrum ([treated] minus [as received]). The difference spectrum is characterized by two groups of peaks, the first reflecting a deficit in treated coal of material up to around $230 \mathrm{Da}$. That deficit is then replaced by a surplus at higher molecular weights. Control runs with no water showed some thermal effect, but the net effect from the presence of liquid water was clearly evident.

The elemental composition of the coals was unchanged after the $150^{\circ}$ and $250^{\circ} \mathrm{C}$ treatments, but the $350^{\circ}$ treatment brought about a $30 \%$ loss of oxygen. The change corresponded to loss of the elements of water (loss of "OH" actually seemed to fit the analytical data somewhat better). The water loss takes place both in the presence and in the absence of added water, but it is noteworthy that the loss in the hydrothermal runs is occurring at a partial pressure of water of about $160 \mathrm{~atm}$ and in the presence of liquid water. Therefore, we conclude that the process benefits from some chemical driving force; that is, it must involve the dehydration of chemically bound elements of watsr.

The changes observed here suggest that Wyodak will be substantially activated by pretreatment at $350^{\circ} \mathrm{C}$. The loss of oxygen is not surprising, since since similar fractional losses are known to occur in this temperature region under other pyrolysis conditions, but the loss of oxygen as water in a way that evidently minimizes formation of benzofuran-type linkages and/or other types of crosslinks is a particularly attractive finding. If the effect of hydrothermal pretreatment observed here for thermal coprocessing carries through to continuous unit catalytis conditions, then these findings could very well lead to practical coprocessing benefits. 

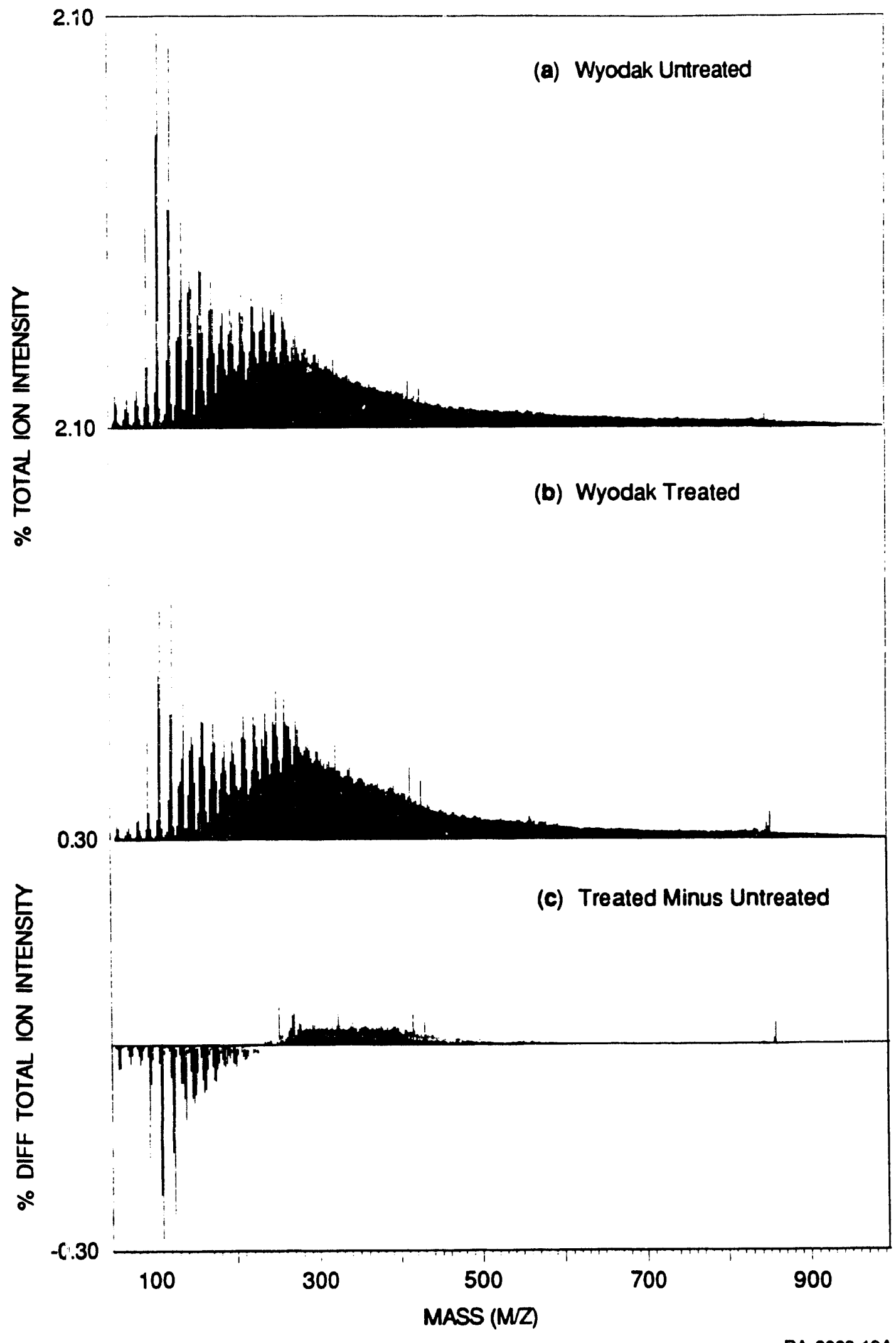

Figure 3. Pyrolysis/FI-mass spectra of Wyodak coal from the Argonne Premium Sample Coal Bank.

(a) untreated, (b) treated, and (c) difference spectrum. 


\section{Possible Chemical Basis for the Impact of Pretreatment}

An important aspect of determining the origin of the pretreatment effect is the pyrolysis chemistry of phenolics, which are recognized as a likely source of regressive reactions. In previous work, 21 we have shown that, unless $\mathrm{H}$-donor solvents are present, phenolics such as catechol and resorcinol undergo rapid coupling reactions, and in some cases these coupling reactions are rapid even in the presence of donor solvents. Subsequently, Grint and Trewhella 22 also demonstrated the facile coupling of naphthol, which is partially mitigated by donor solvents. In the present study, we examined the effect of mineral matter on the coupling reactions of phenolics and how water affected these reactions. We found that the presence of water, or pretreatment of the clay with water, had the beneficial result of limiting subsequent regressive reactions.

In subbituminous coals, statistically one in every ten heavy atoms is a phenolic $\mathrm{OH}$, and many of these are in catechol-based dihydric systems, so cateci ol seemed the most readily identifiable candidate probe molecule for retrograde reactions. We therefore performed most of the experiments with catechol.

Table 4 presents data showing the coupling and deoxygenation tendencies of catechol in the presence and absence of kaolin and the effect of water in modifying these reactions. As can be seen from these data, the addition of water markedly retards the condensation of the phenols. For instance, after reaction at $350^{\circ} \mathrm{C}$ for $3 \mathrm{hr}$, a mixture of catechol and kaolin (entry 4) contains only $38 \%$ of the original catechol (and $4 \%$ phenol), compared with $96 \%$ and $1 \%$ with water added (entry 5). At $400^{\circ} \mathrm{C}$, with a mixture of clay and catechol (entry 2 ), only $2 \%$ of the catechol was recovered, while in the presence of water, (entry 3 ) $84 \%$ was recovered.

The FI mass spectra of these runs illustrate these differences still further. For instance, Figure 4(a) shows the mass spectrum from run 6 where catechol and kaolin were treated at $300^{\circ} \mathrm{C}$ for $5 \mathrm{~h}$. Although the reaction mixture is complex, several prominent masses suggest various phenolic coupled products. In Figure 4(b), which is the spectrum from run 7 of catechol and kaolin in the presence of water, we see that many fewer retrogressive reactions have occurred. Figure 5 illustrates possible self-coupling pathways for the polymerization of catechol that give masses 216 , 218 , and 220. 
Table 4

EFFECT OF WATER ON MASS BALANCE WITH CATECHOL AND CLAY

\begin{tabular}{llccccc}
\multirow{2}{*}{$\begin{array}{l}\text { Entry } \\
\text { No. }\end{array}$} & Description & & & \multicolumn{3}{c}{ Mass Balance (Mol\%) } \\
\cline { 5 - 7 } & Temp. ${ }^{\circ}$ C) & Time $(\mathrm{h})$ & Catechol & Phenol & Remainder \\
\hline 1 & Catechol & 400 & 1 & 75 & 18 & 7 \\
2 & Catecholkaolin & 400 & 1 & 1.8 & 0.2 & 98 \\
3 & Catecholkaolin/water & 400 & 1 & 84 & 3 & 13 \\
4 & Catecholkaolin & 350 & 3 & 38 & 4 & 58 \\
5 & Catecholkaolin/water & 350 & 3 & 96 & 1 & 4 \\
6 & Catecholkaolin & 300 & 5 & 83 & 8 & 9 \\
7 & Catecholkaolin/water & 300 & 5 & 100 & 0 & 0 \\
8 & Catechol/ & 300 & 5 & & & \\
\hline
\end{tabular}

One likely explanation of how water might suppress coupling is that the water moderates the acidity of the clay, making it less effective in these coupling reactions. To test this possibility, we pretreated some of the clay itself with water (and then removed the superficial water) before adding the catechol. As seen in Table 4, this treatment resulted in some suppression of the coupling, but not nearly as much as observed when water and catechol were simply added together. This result suggests that water plays a role in the coupling reactions themselves, rather than acting merely by altering the acidity of catalytic clay surfaces.

To help determine at what stage water might be intervening to suppress coupling, we conducted some experiments in the presence of $18 \mathrm{O}$-labeled water. Catechol was heated with $\mathrm{H}_{2}{ }^{18} \mathrm{O}$ at $350^{\circ} \mathrm{C}$, with and without kaolin present. In both cases, the recovered catechol (as well as the phenol produced) was found to have incorporated labeled oxygen. The extent of label incorporation was somewhat greater in the presence of kaolin. We are aware of no precedents for such a reaction and can envision only two possible routes for this unusual incorporation. The first is a simple nucleophilic substitution of water on the catechol. However, such a reaction should be more facile on phenol itself, which does not have the additional electron-releasing OH group. The chemistry of phenol is well reported and since such a reaction is not in the literature, we can only assume that a nucleophilic substitution mechanism is unlikely. Therefore, as a second possible 


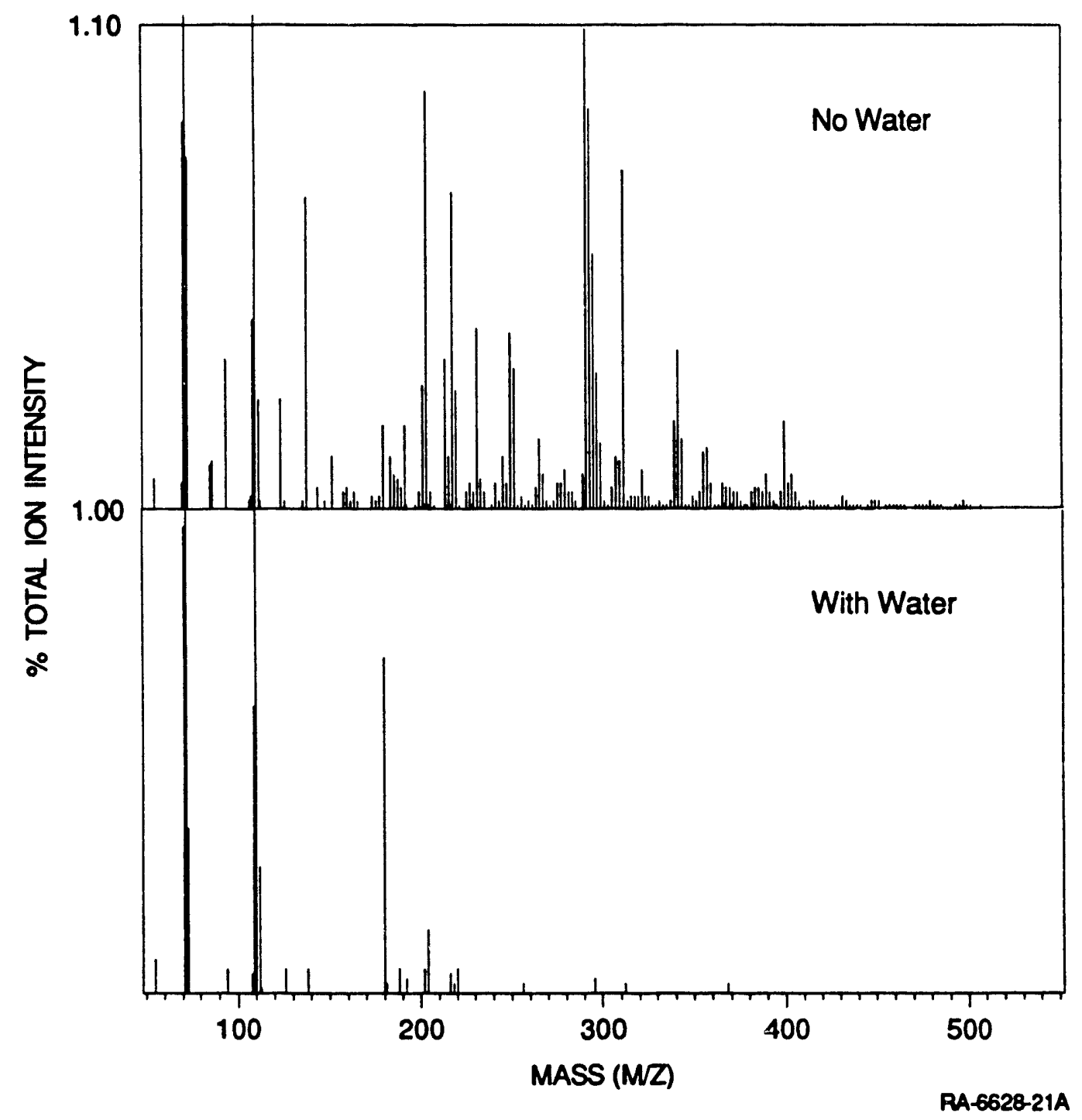

Figure 4. Fl-mass spectra of products from heating catechol in the presence of kaolin at $300^{\circ} \mathrm{C} / 5 \mathrm{~h}$.

(a) in the absence of water, (b) with added water. 
route, we suspect that the exchange comes about from reaction of water with a dimeric intermediate step from which one molecule of water has already been lost. We further suspect that the role of kaolin for the polymerization reaction is to absorb or renove the water in some way so that the reaction is no longer reversible. However, the presence of water reverses the effect. Clays are well known to promote dehydration reactions, so such an explanation is reasonable.

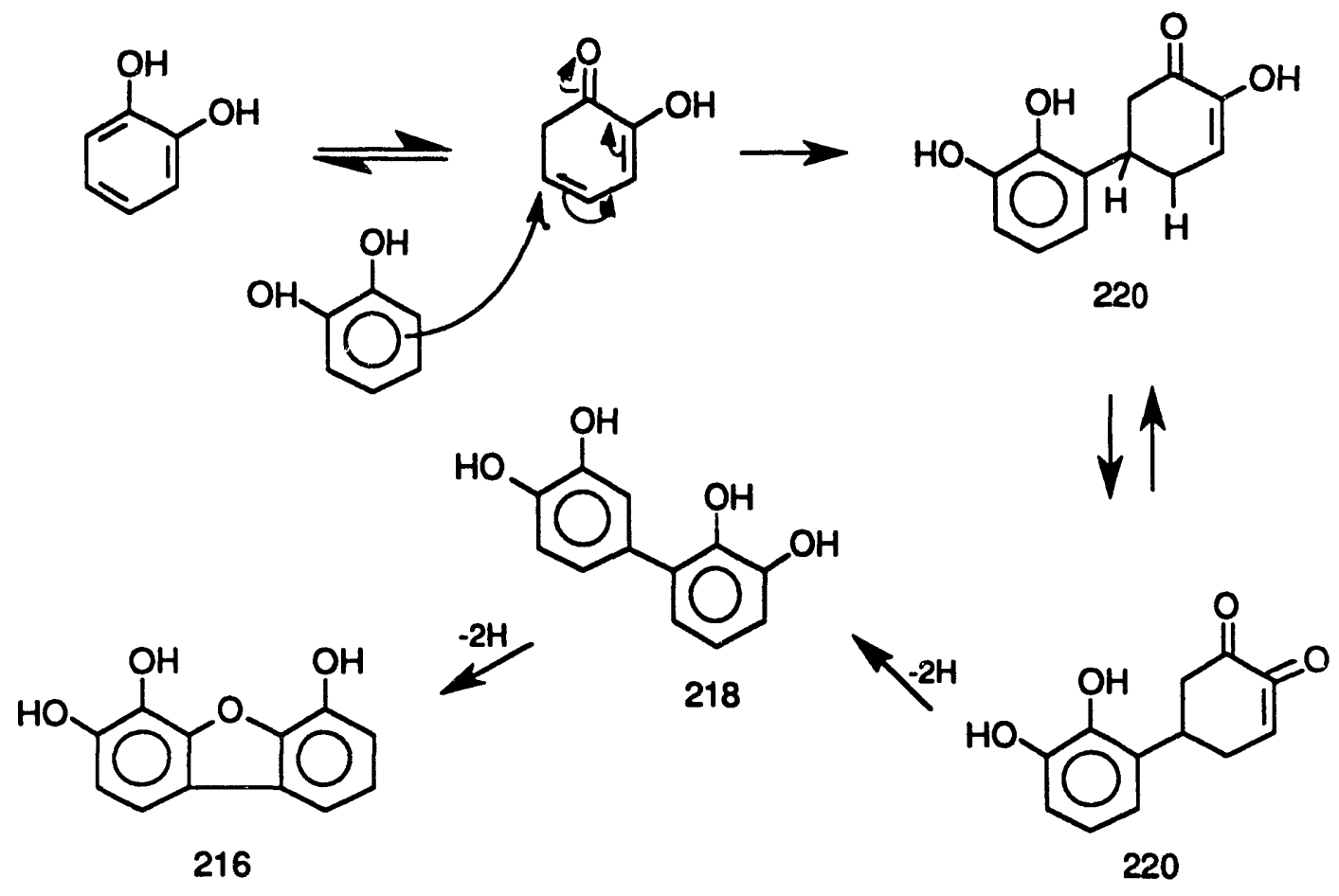

RM-6628.24

Figure 5. Possible self-coupling reactions of catechol. 


\section{TASK 3: CHEMISTRY OF SYNERGY}

\section{BACKGROUND}

In the context of coprocessing, the word "synergy" has been used in different senses, resulting in miscommunication. Sometimes, the mere occurrence of "synergy" (used in the broadest sense of the word) has been put forth as a justification for coprocessing as a more favorable option than separate processing of coal and resid streams. Critics have objected strongly to this idea, reminding us that the real justification should follow not from any "synergy" (defined only in terms of any increased conversion) that might exist, but from the economics of the two options.

Obviously, when coals and hea: y oils are processed together, they bring to the process components that will interact with each other. We merely argue that, to the extent there are positive interactions, they ought to be understood so that they may be maximized. One type of synergy in coprocessing is already well recognized: the metals-sequestering tendency of the insoluble organic matter that inhibits catalyst deactivation. Another category of positive interactions in coprocessing is that in which the nature of the reaction medium is changed by the presence of coal in a way that improves coal conversion and distillate yield as well as decreases coke yield. This type of interaction has been documented over several years by researchers at HRI, among others. 5,10,23

In this task our goal was to help understand this latter type of positive interaction. These interactions are presumed to take place primarily between the organic constituents of the two feedstocks, but it is not clear whether they result primarily from physical solvency factors, or whether substantial chemical factors are involved. Our approach to answering this question involved (1) examining literature data on coprocessing, (2) using suitable model compounds to enhance our understanding to the interaction between aromatic and aliphatic fossil fuel components, and (3) using probe molecule experiments in which real feed and recycle streams were tested for their ability to bring about certain measurable chemical changes (e.g., strong C-C bond cleavage).

Task 3 derives in part from earlier work, in which the solvent was recognized to be an active reagent bringing about bond cleavage. ${ }^{24,25}$ In that work, we suggested that increased aromaticity of the liquefaction medium, long recognized to improve "hydrogen-shuttling," does so 
in a way that leads to increased C-C bond cleavage during the shuttling itself. ${ }^{25}$ Furthermore, we have suggested that some polycyclic aromatic hydrocarbon (PCAH) are good enough $\mathrm{H}$-shuttlers to use hydrogen directly from aliphatic structures of the resid for inducing cleavage of strong bonds. 226,27 This cleavage results from transfer of hydrogen to critical ipso positions via several pathways, including radical hydrogen-transfer (RHT).

\section{RESULTS}

To help provide a baseline for distinguishing between the benefits resulting from chemical and physical solvency factors, we conducted some experiments in homogeneous systems, from which we could easily extract the impact due to chemical changes. We synthesized a series of benzyl aromatics and studied their cleavage in a mixture of anthracene and dihydroanthracene. Cleavage rates for the different substrates increase in the order diphenylmethane $<$ benzylnaphthalene < benzylphenanthrene < benzylpyrene, increasing by almost four orders of magnitude through the series. The log of observed first-order rate constants correlates linearly with the exothermicity of $\mathrm{H}$-addition to the aromatic bearing the benzyl group. These results are in excellent agreement with our previously modeled results, from which we had projected that the critical $\mathrm{H}$-transfer step in all but the single-ring system (diphenylmethane) would be the direct $\mathrm{H}$ transfer step, radical hydrogen-transfer. ${ }^{26}$ The experimental results further show the generality of induced bond cleavage and buttress our view of the possible chemical basis of improvements resulting from increased aromaticity. These results, which are described in Appendix E, support our the earlier suggestion 27 that the basis of the synergy may in fact lie in the increased levels of certain types of hydroaromatic species (e.g. pyrenes, perylenes) that become more rapidly available when coal is one of the feedstocks and when either an external or internal recycle is used. Although it has been recognized for many years that increased PCAH content increases the hydrogen-shuttling capability of the liquefaction medium, w/e have only recently suggested 27 the further possibility that pyrene-like PCAH may be sufficiently effective as $\mathrm{H}$-shuttlers to even utilize hydrogen from the hydrogen-rich, but kinetically poor, portion of the resid structures, namely, the paraffinic and naphthenic groups and side-chains.

During, this project, DOE-sponsored coprocessing development studies at Universal Oil Products (UOP) dramatically illusirated the beneficial impact of adding a recycle stream to a plugflow reaction system. This development highlighted unanswered questions about the role of the medium in a heavily catalytic process and reopened the question of once-through versus recycle strategies for coprocessing. Favored explanations for the improvements ranged from improved 
hydrodynamics (increased space velocity), to improved physical solvency, to enhanced hydrogentransfer (or some combination of the three). Unless the explanation for the improvements observed at UOP were to lie entirely with improved hydrodynamics, those improvements are a clear indicator of positive interactions between the nature of the reaction medium into which the fresh feed comes. Thus, the questions of how to enhance and thereby take maximum advantage of this significant process improvement fit exactly into the objective Task 3. Accordingly, we arranged with John Gatsis of UOP to obtain samples of the fresh feed and the recycle streams. With these samples we planned to perform probe molecule experiments under conditions where physical solvency is not a factor,and to thereby determine the extent to which the process improvements result from bond cleavage due to enhanced hydrogen transfer. These were to be coupled with field ionization mass spectrometric analysis of the various feed streams, which would directly give a fairly good measure of PCAH distributions in these streams.

Unfortunately, due to schedule changes and other delays at UOP, we were unable to obtain these samples before the end of the project. Consequently, we performed instead some additional studies with probe molecules and model solvent components to clarify the reactivity-selectivity patterns for bond cleavage to various sized PCAH, and as well some $\mathrm{H}_{2}{ }^{18} \mathrm{O}$ isotopic exchange studies pertinent to the Task 2 objective.

\section{REFERENCES}

1. A. S. Hirschon, D. S. Ross, and L. L. Ackerman, "Low Severity Conversion of Activated Coal," SRI Quarterly Report, DOE/PC/79936-4 (October 1988).

2. I. Mochida, K. Iwamoto, T. Tahara, Y. Korai, H. Fujitsu, and K. Takeshita, Fuel 1982, $61,603$.

3. R. A. Graff and S. D. Brandes, Energy Fuels 1987, 1, 84-88.

4. P. Bienkowski, R. Narayan, R. Greenkorn, and K.-C. Chao, Ind. Eng. Chem. Res. 1987, 26, 202.

5. Comolli, A. G.; Johanson, E. S.; Panvelker, S. V., Proceedings of Direct Liquefaction Contractors' Meeting, September 24-26, 1990, Pittsburgh, PA, p. 116.

6. P. S. Maa, R. C. Neavel. and I. W. Vernon, Ind Eng. Chem. Process Des. Dev. 1984, 23, 242-250.

7. R. A. Winschel, private communication, 1989. 
8. A. V. Cugini; R. G Lett; I. Wender, Energy Fuels 1989, 3, 120.

9. F. P. Burke; R. A. Winschel; M. S. Lancet, "Stable Carbon Isotope Analysis of Coprocessing Materials," Quarterly Technical Progress Report, US DOE contract No. DEAC22-88PC8800 (January 1989).

10. J. B. Mclean; J. E. Duddy, Am. Chem. Soc., Div Fuel Chem. Preprints 1986, 31(4), 169.

11. F. Khorasheh; H. A. Rangwala; M. R. Gray; I. G. Dalla Lana, Energy and Fuels, 1989, 3, 716.

12. P. E. Sayage; M. T. Klein; S. G. Kukes, Energy and Fuels, 1988, 2, 619.

13. Y. Miki; S. Yamadaya; M. Oba; Y. Sugimoto, J. Catal., 1983, 83, 371.

14. F. O. Rice, and K. F. Hertzfeld, J. Am. Chem. Soc. 1934, 56 , 284; F. O. Rice, K. F. Hertzfeld, J. Chem. Phys. 1939, 7, 671; A. Kossiakoff; F. O. Rice, J. Am. Chem. Soc., 1943, 65, 590.

15. R. L. Miller, M. E. Armstrong, and R. M. Baldwin, Am. Chem. Soc. Div Fuel Chem. Preprints 1989, 34(3), 873-880.

16. H. F. Silver, W. S. Frazee, "The Effect of Drying on the Liquefactions of Subbituminous Coal," presented at the 10th Annual EPRI Contractors' Conference on Clean Liquid and solid Fuels, Palo Alto, CA, April 23-25.

17. U.S. Statutory Invention Registration No. 869, June 3, 1986, Fuel Processing Technology $11,13,1985$.

18. Derbyshire, F. J., A. Davis, M. Epstein, and P. Stansberry, "Temperature-Staged Catalytic Coal Liquefaction", Ftiel 1986651233.

19. S. A. Fouda, J. F. Kelly, and P. M. Rahimi, Am. Chem. Soc. Div Fuel Chem. Preprints 1988, 33(1), 178-181.

20. T. Suzuki; O. Yamada; Y. Takehaski; Y. Watanabe, Fuel Process Technology, 1985, 10, 33-43.

21. D. F. McMillen; S.-J. Chang; R. H. Fleming; R. M. Laine; R. Malhotra; E. Nigenda; W. C. Ogier, "Effect of of Amine Solvents and Oxygen Functionalities on Coal Liquefaction," EPRI Research Project 2147-5, 1985.

22. A. Grint; M. J. Trewhella, Fuel 1988, 67, 1135.

23. S. Panvelker, private communication, 1989.

24. D. F. McMillen; R. Malhotra; S. -J. Chang; R. H. Fleming; W. C. Ogier; S. E. Nigenda, Fuel 1987, 66, 1611.

25. D. F. McMillen; R. Malhotra; G. P. Hum; S. -J. Chang, Energy Fuels 1987, 1, 193. 
26. D. F. McMillen; R. Malhotra; D. S. Tse, Energy Fuels 1991, 5, 179.

21. R. Malhotra; D. F. McMillen, Energy Fuels 1990, 4, 184. 
UAVUUS, RUSS, DCNALU 5. MCMULACI, KUTUUAMAN MALHOI KA, ALBERT S. HIRSCHON, AND DORIS S.TSE

SRI Internmional

Menlo Perk, CA 94025

\section{INTRODUCTION}

We are conducting sudies on the effects of hydrothermal pretreament of coal on coprocessing yields and product quality (US DOE Contract No. DE-AC22-88PC 888 02). The term hydrothermal refers to aqueous media heared to the critical point of waler $\left(374^{\circ} \mathrm{C}\right)$ under conditions a the liquid/vapor boundary where a liquid phase is maintained. The term is also applied to supercritical water at liquid-like densities. The work is part of a larger program on the effects of hydrothermal media on coal overall, and a companion paper in these proceedings reports on the effects on the pyrolytic properties and products of coal (Ross, et al., 1989).

Our coprocessing effort is work in progress, and is being conducted with a somewhat weathered Illinois No. 6 coa (PSOC 1098), and Argonne premium samples of both Ilinois No. 6 and Wyodak coals. The residuum is a Maya ATB. The hydrothermal conditions used are $250^{\circ} \mathrm{C} 30$ min under 500 psi $\mathrm{N}_{2}$, and the samples are protected from the atmosphere following the pretrearment. the coprocessing nuns are conducted in a stirred autoclave at $425^{\circ} \mathrm{C} 30 \mathrm{~min}$, and analyses include studies with SRTs field ionization mass spectrometer (FIMS).

\section{RESULTS}

Earlier Work. In is helpful to begin with a summary of findings developed earlier in coal liquefaction studies, conducted with PSOC 1098. Elemental and ash analyses for both the asreceived coal and the pretreated samples are presented in Figure 1; the 0 -values were obcained by
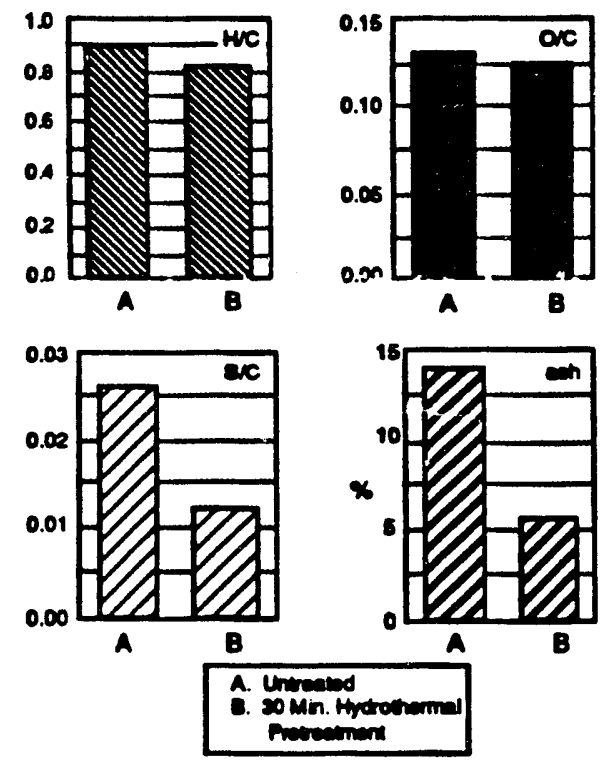

Figure 1. Analytical data for unpretreated and bydrochermally pretreated nlinois No. 6 coal.

direct O-analysis. The H/C and $\mathrm{O} / \mathrm{C}$ ratios changed only slightly, but the bulk sulfur content was substantially roduced. The change in bulk sulfur was maiched by lowered ash levels, the pretreatment affecting about $60 \%$ reductions in both cases. The similarity demonstrates that ash reduction by the hydrothermal medium mus involve removal primarily of sulfur-containing material, most likely sulfare. These results are qualitatively similar to those of Rozgony a 1.(1988), who reported 39\% and 31\% reductions, respectively, in total sulfur and ash for a binuminous coal after hydrochermal treatment a $292^{\circ} \mathrm{C} 40 \mathrm{~min}$. Our higher values may be due to our lower temperaure, which minimizes thermal degradation of the organic portion of the coal.

Work with scanning electron microscope (SEM) and energy dispersive $X$-rny (EDX) showed the sarting coal to be present in perticles of nominally $50.200 \mathrm{um}$, with separate particles representing both the bulk organic and bulk mineral phases. The hydrothermal trearment, however, aubstantially decreased the particle size of the coal, with the formation of a considerably fines fraction with nominal particle sizes below 1 um. A profound change occurred in the bulk mineral phase, which became tragmented and irregular in appearance.

$$
\text { A-1 D S ROSS }
$$


Considerable quantities of $\mathrm{Fe}, \mathrm{A}$ and $\mathrm{Si}$ were seen in the organic phase, an observation in line with the split of the mineral components in coal berween the bulk arganic and mineral phases discussed by Finkelman (1988). Allen and VanderSande (1984) have estimated that mineral maner in the mongir whage moy remmsent in to 15\% of the rocal quantity of mineral material in cosal. A discribution of such a fine mineral material throughout the crganic phase leads to a significant interfacial volume and could be connected to the effects of hydrothermal pretreament. This view is in line with suggestions by Mraw et al. (1983) tha mineral material within the arganic phase could be significant to the behavior of coal in general

The effects of hydrothermal pretreatument on "iquefaction were audied in both $\mathrm{CO} /$ water and $\mathrm{H}$ don or (tetralin) systems. We found that $30 \mathrm{~min}$ pretreatment provided remarkable improvement in convertibility in the former, increasing the convertibility of nlinois No. 6 coal from $30-40 \%$ toluene-soluble products (TS) to values around 70\% ss shown in Figure 2. FIMiS analysis howed that pretreatment increased the number average molecular weight $\left(\bar{M}_{0}\right)$ of the TS fractions from 411 to $\mathbf{4 8 5}$ dalton. This in/sease reflects the conversion of lorger quantities of the sturting coal, increasingly more difficult to liquefy. Such effects have been reported by Farcasiu and coworkers (1977) for increased liquelaction severity. In the present case it appears that the pretreatment conditions the cos to undergo greater conversions a a constant severity.

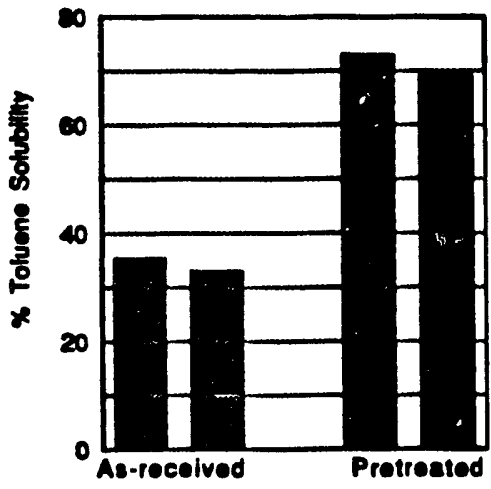

Figure 2. Conversions of pretreated and as-received nlinois No. $6 \mathrm{cos}$ in $\mathrm{CO} / \mathrm{H}_{2} \mathrm{O}$ at $\mathrm{pH} 13$.

The yield benefits were not as dramatic in the tetralin conversions, as shown in Figure 3, although the quality of the product was changed considerably. (The pretreated material was only superficially dried to avoid the risk of altering the material through excessive drying, and control runs included conversions nis "vith stdes water, resuling in the designations "dry" wid "wer" tetralin.) For the TS fractions pretreatment increased $\bar{M}_{n}$ from 464 to 479 datton, and at the same

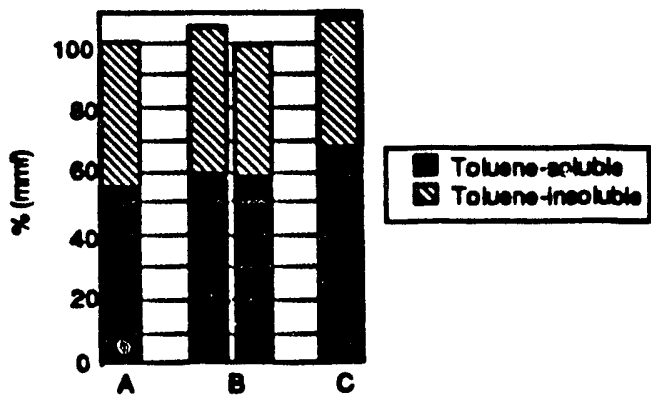
A. As-recournod cool aty worln
B. Ab-recoived con metwiln
C. Protrestied ond
ory tringin

Figure 3. Conversions of pretreared and as-received llinois No. 6 coal in tetralin and $\mathrm{H}_{2}$ ( 500 psi cold). A. As-received coal/dry tetralin. B. Asreceived coal/wet tetralin. C. Pretreated coal/ dry tetralin.

time decreased the temperanure a half volntility from $250^{\circ}$ to $205^{\circ} \mathrm{C}$. This result suggests that the pretreatment brings about a product of lowered polarity, a possibility to be confirmed in further work. Figure 4 shows a breakdown of $\left(\bar{M}_{\mathrm{n}}\right)$ over temperaure intervals in terms of the difference 
$\bar{M}_{n}$ [pretreated] - $\bar{M}_{n}$ [wet tetralin], showing the $\bar{M}_{n}$ differences to be concentrated in the more volatile half of the fractions.

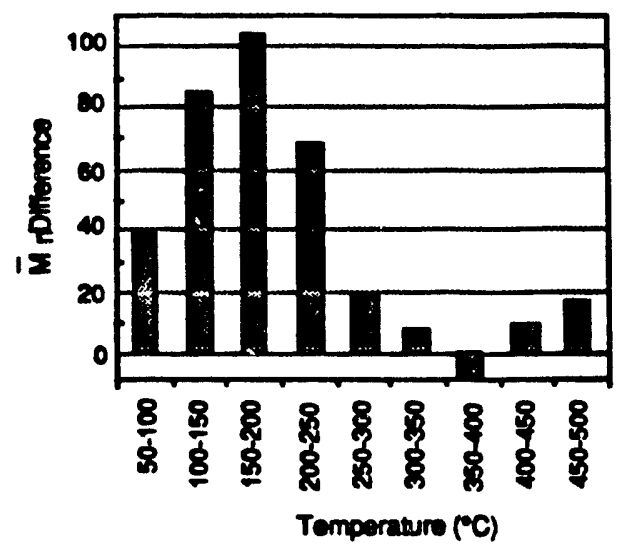

Figure 4. Comparison of tohuene-soluble fractions from conversions of pretreated and as-received coal.

Coprocessing Work. With these results as a backdrop, we are conducting the coprocessing studies described here, seeking the degree to which hydrothermal pretreatment of the coal increases its dissolution in the ATB. Our diagnostics include simple solubility determinations of the product. and detailed FIMS analyses. The runs are conducted with a ATB/coal ratio of $6 / 1$, and 1200 psi $\mathrm{H}_{2}$ (cold).

The results from some experiments with both the Dlinois and Wyodak coals are presented in Table 1. In a control run the ATB was treated at the coprocessing conditions in the absence of coal.

Table 1

Coprocessing Studies at $425^{\circ} \mathrm{C} / 30 \mathrm{Min}$ and $1200 \mathrm{psi} \mathrm{H}_{2}$ (cold)

\begin{tabular}{|c|c|c|c|}
\hline \multirow[b]{2}{*}{ Stanting } & \multicolumn{3}{|c|}{ THE-Insoluble (e) } \\
\hline & ATB alone & As-reaceived & + cogl \\
\hline $30 \mathrm{~B}$ ATB & 2.3 & - & - \\
\hline $\log _{\mathrm{g}} \mathrm{ATB}+\infty$ & & & \\
\hline $\begin{array}{l}58 \text {.Jl. No. } 6 \\
\text { (PSOC 1098) }\end{array}$ & - & 5.6 & 7.0 \\
\hline $\begin{array}{r}5, \text { m. No. } 6 \\
\text { (Argoune Prem.) }\end{array}$ & - & 3.3 .3 .8 & 3.3 .3 .8 \\
\hline $\begin{array}{l}11 \text { \& Wyodak } \\
\text { (Argoune Prem.) }\end{array}$ & - & 6.6 & 7.6 \\
\hline
\end{tabular}

There is no substantial effect of pretreatment apparent from the data, although in is difficult to discem the degrees to which the coal has been converted from simple solubility tests.

More significant are the FDMS results with PSOC 1098, presented in Figure 5. The spectra are for the respective full liquid products, and the broadening of the responses to higher molecular weights reflects the introduction of coal-derived meterial into the liquid. Spectra b and $c$ appear qualitatively similar. However as shown in Table 2 and Figure 6, the pretreatment does affect the number average molecular weights of the products. The table shows a significant increase in the overall $\bar{M}_{n}$, and the figure, presenting the $\bar{M}_{n}$ as a function of the fraction of the distilled products, demonstrates that the ectivity is concentrated in the heavier ends of the product. 

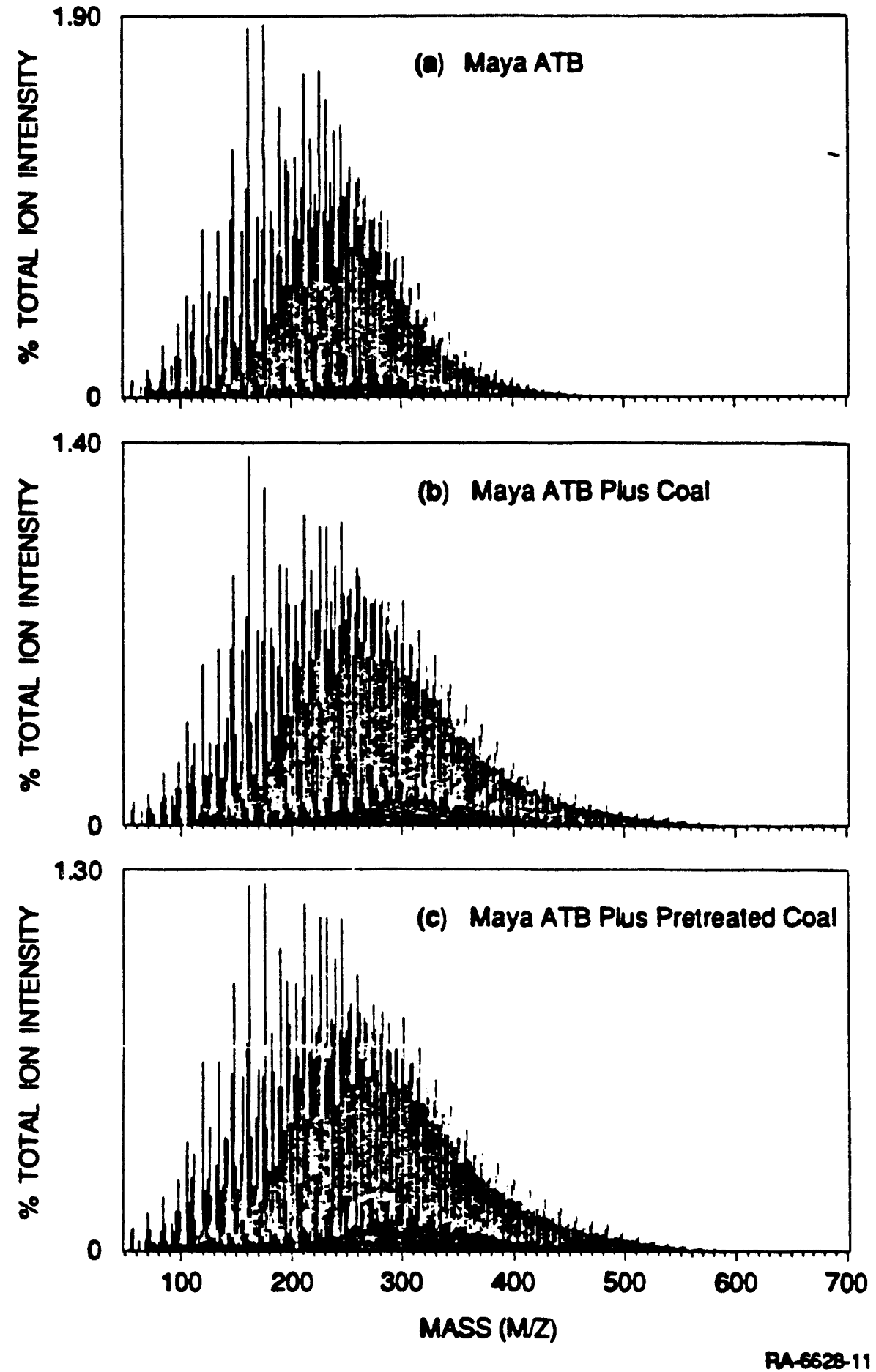

Figure 5. FIMS spectra for as-received and pretreated mlinois No. 6 coal. 
Table 2

Overall Number Average Molecular Weight Values for Coprocessing Products

\begin{tabular}{|c|c|}
\hline Simple & $\bar{x}_{2}$ (dalion) \\
\hline Myn ATB & 356 \\
\hline$\underset{\text { Moll }}{\text { MatB }}+$ & 377 \\
\hline $\begin{array}{l}\text { Maye ATB + } \\
\text { preted ocond }\end{array}$ & 411 \\
\hline
\end{tabular}

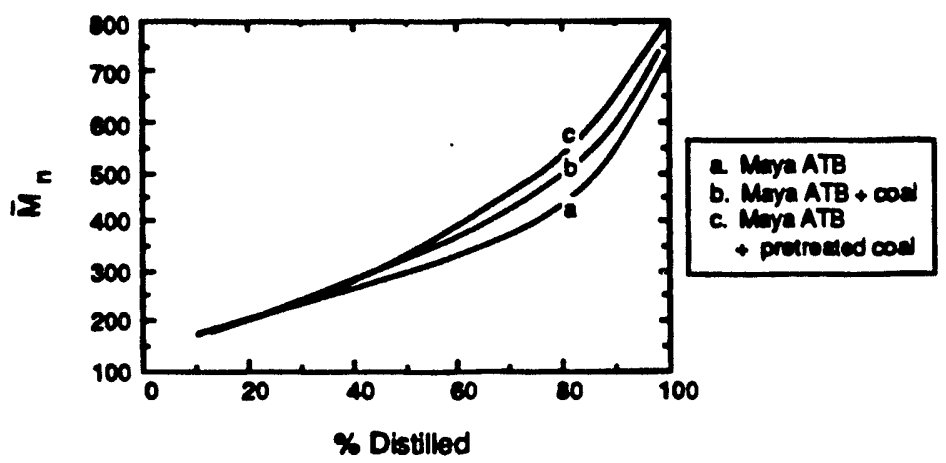

Figure 6. Number average molecular weight ys distillation fraction.

While these data are preliminary, they suggest that pretreatment conditions the coal to boost its activity in the coprocessing. Additional work is underway to confirm these results, and to assess the full action of hydrothermal pretrearment and is ulamate value.

ACKNOWLEDGEMENT: We are plessed to acknowledge the suppon of the U.S. Department of Energy of this work.

\section{REFERENCES:}

Allen, R. M. and VanderSande, J. B., Fuel, 3, 24-29 (1984).

Farcasiu, M., Mitchell, T. O., and Whitehurst, D. D., Chemtech 1977, 2, 680

Finkleman, R. B., Scanning Microscopy, 2 (1), $97-105$ (1988).

Mraw, S. C. DeNeufville, J. P., Freund, H., Baset, Z., Gorbaty, M. L., and Wright, F. J. in Coal Science, Vol. 2, J. Larsen, M. L. Gorbaty, and I. Wender, Eds., Academic Press, New York, 1983, pp. 1-26.

Ross, D. S. and Hirschon, A., these proceedings, 1989. 


\title{
WEAK LINKS AND INTERFACIAL CHEMISTRY IN COAL
}

\author{
David S. Ross, Albert S. Hirschon and Thomas K. Green \\ SRI International \\ Menlo Park, CA 94025 USA
}

KEY WORDS: Interfacial, Hydrothermal, Free radical

\section{INTRODUCTION}

The liquefaction of coal is conventionally viewed as involving the thermal generation of free radicals, followed by the capping of the radical sites by H-donors.

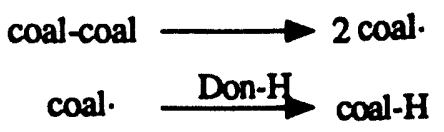

Indeed, the reactive site most typically introduced into models suggested for the organic phase of coal is a thermally weak bond such as the central bond in bibenzyl or benzyl phenyl ether (ref. 1). Our work has dealt with the issue of how correct this model is.

Our studies have followed two paths using Illinois No.6 coal. First, we have conducted chemical studies seeking the degree of free radical formation in the coal during thermolysis. Second, we have sought other reactive centers in the coal using the effects of hydrothermal treatment of coal on its thermolysis.

\section{RESULTS AND DISCUSSION}

\section{Test for Thermally Generated Free Radicals}

To test for the presence of weak bonds we conducted experiments in small reactors at $400^{\circ} \mathrm{C}$ in which known quantities of coal and bibenzyl $\left(\mathrm{PhCH}_{2}-\mathrm{CH}_{2} \mathrm{Ph}\right)$ were pyrolyzed together, with $\mathrm{D}_{2} \mathrm{O}$ as the medium. The bibenzyl was fully in the vapor phase, and the heavy water was above its critical temperature. Bibenzyl provides known, controllable steady-state quantities of bibenzyl radical ( $\mathrm{PhCH} \cdot-\mathrm{CH}_{2} \mathrm{Ph}$ ) through a sequence of reactions following its initial scission to benzyl radical $\left(\mathrm{PhCH}_{2}\right)$, and the kinetics of that process have been thoroughly developed. We reasoned that the thermally generated radicals in the coal would effectively scavenge the bibenzyl and benzyl radicals. Then subsequent analysis of the quantities of recovered bibenzyl and toluene would provide quantitative information on the radical site densities in the coal.

Analysis was simplified by our establishing first that mass transport of the radicals to the coal was not kinetically significant. Also helpful was the use of the known quantities of phenolic functions in the coal, which are immediately deuterated at $\mathrm{O}$ by the medium, and the independently 
determined rate of reaction between bibenzyl radical and $\mathrm{Ph}-\mathrm{OD}$. The coal-bound phenolics, expected to compete for the gas $\mathrm{f}$ hase radicals, thus served as an internal standard.

The results were surprising. We found essentially no scavenging of gas phase radicals by the coal. The transfer from phenolic OD on the other hand took place as expected. A quantitative analysis of the data showed that the levels of weak bonds displayed in common coal structures would have to be reduced by about three orders of magnitude to account for the lack of activity we observed.

We conclude that there is no evidence to support the presence of substantial quantities of weak bonds in the organic phase of coal. We have accordingly sought other potential sites for reaction, and have tested the possibility of an extensive interphase volume in coal at the boundaries of the organic phase and the ultrafine mineral component embedded in the organic phase.

\section{Hydrothermal Treatment}

The hydrothermal treatment of coal has been reported by a number of workers including Bienkowski et al. (ref. 2), and Brandes and Graf (ref. 3,4). Our studies were conducted with Illinois No. 6 coal (PSOC 1098) treated in liquid water at $250^{\circ} \mathrm{C}(\sim 38 \mathrm{~atm})$. The volatility properties of both the as-received and treated coal were compared by field ionization mass spectrometry (FIMS). The samples were heated slowly in the inlet assembly from ambient to $500^{\circ} \mathrm{C}$, and the signal was recorded throughout the heating period. The total volatile yields were virtually identical, $22 \%$ and $23 \%$ of the as-received and treated samples, respectively, and the results are shown in Figure 1, where the number average molecelar weight of the evolving material, $\overline{\mathbf{M}}_{\mathbf{n}}$, is plotted with temperature.

The profile for the as-received coal steadily increases to a single maximum with increasing temperature, a behavior expected from the thermolysis of a highly crosslinked material. The profile for the treated material, on the other hand, appears to be the sum of profiles for the asreceived coal and for a second, more volatile quantity of condensibles

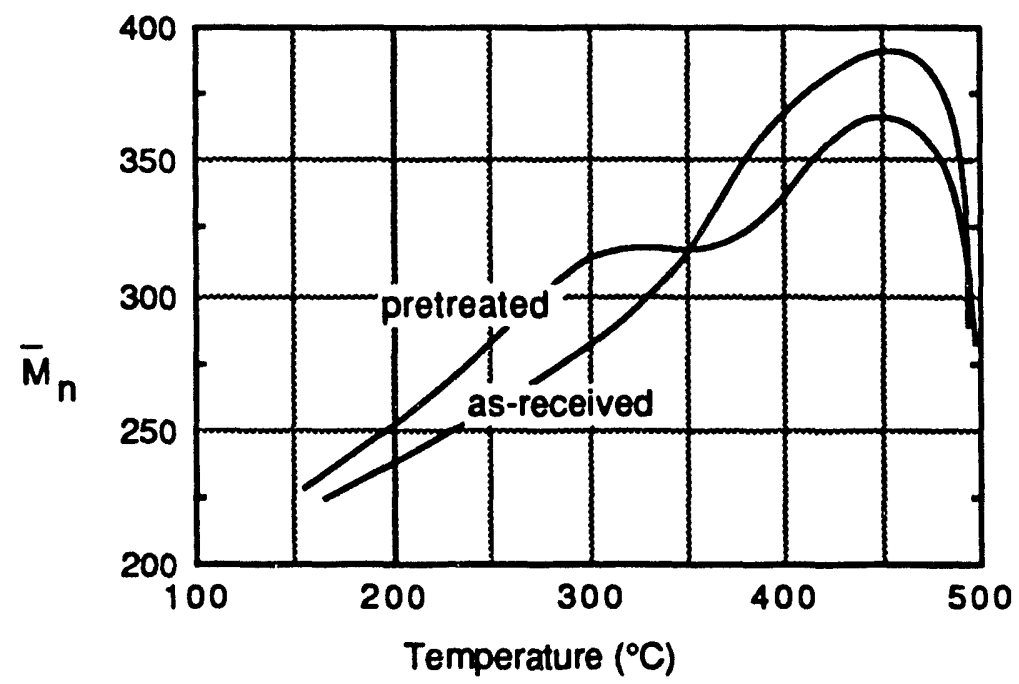

Figure 1. FIMS analysis of pretreated and as-received Ilinois No. 6 coal.

produced by the pretreatment. This view consistent with the fact that the number average molecular weight of the volatiles is reduced from 347 dalton for the tar from the as-received material to 326 dalton for the treated coal tar. 
Additional FIMS data are shown in Figure 2, which shows the differences in the distribution of molecular weights in the treated and as-received samples. Specifically the figure plots the response difference, (treated) - (as-received), against molecular weight intervals up to 750 dalton. The figure demonstrates a broad enrichment in lower molecular weight material at the expense of higher weight tars. Inspection of the FIMS data shows that the primary "early" products are simple arenes, areneols, and arenediols. Thus the behavior is not merely a release of trapped material. Rather, the results suggest that the treatment changes the coal in some manner such that the tar precursors generate additional lower weight material from components that would otherwise proceed to high molecular weight volatiles.

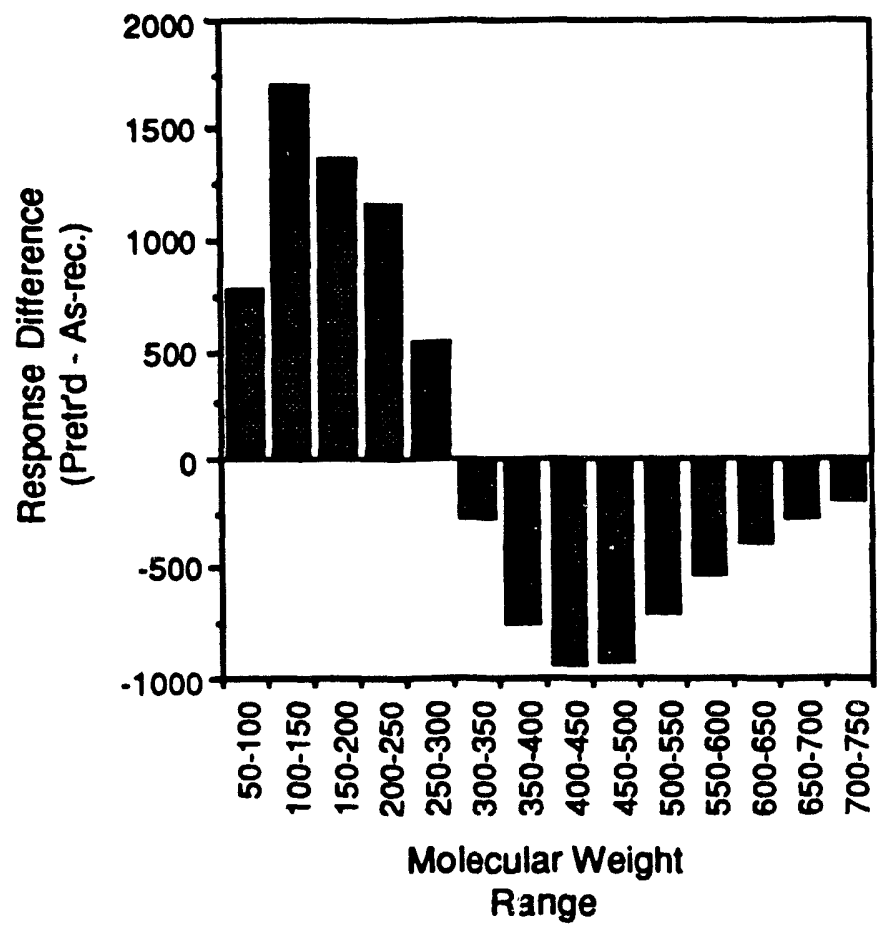

Figure 2. FIMS response differences as a function of molecular weight range. The response data have been normalized so that the values from the two materials can be directly compared.

These results demonstrate that the coal contains regions with structural components significantly reactive under the hydrothermal environment, and the activity is reminiscent of findings in studies of accelerated maturation of oil shale where hydrothermal treatment (hydrous pyrolysis) leads to the production of petroleum hydrocarbons (ref. 5). Recent results by Hoering (ref. 6) are particularly applicable to the present case. In that work the treatment of preextracted Messel shale with water at $330^{\circ} \mathrm{C} / 3$ days generated petroleum hydrocarbons including long chain normal alkanes, aromatics, and biomarkers when heated in liquid water at $330^{\circ} \mathrm{C} / 3$ days. Control runs eliminated virtually all sources of these products from the pure organic phase including trapped material and simple kerogen pyrolysis, and suggest that chemistry at the mineral/organic interface is responsible. 


\section{CONCLUSIONS}

It has been estimated that the ultrafine mineral component in coal can be up to $15 \%$ of the total mineral content (ref 6), and the similarity of our results with coal to those for oil shale suggest that the reactive mineral'organic interfacial volume in coal could be substantial. While the mechanisms for reactions within the interphase are yet to be developed, our results suggest that attention be applied to this feature of coal in considerations of structural effects on both liquefaction and coal pyrolysis.

\section{REFERENCES}

1. J. H. Shinn, Fuel, 63(9), 1187-1196 (1984).

2. P. R. Beinkowski, R. Narayan, R. A. Greenkorn, and K-C Chao, Ind. Eng. Chem. Res., 26, 202-205 (1987).

3. S. D. Brandes and R. A. Graff, Am. Chem. Soc. Div. of Fuel Chemistry Preprints, 32 (3), 385-393 (1987).

4. R. A. Graff and S. D. Brandes, Energy and Fuels, 1, 84-88 (1987).

5. T. I. Eglinton, S. J. Rowland, C. D. Curtis, and A. G. Douglas, Org. Geochemistry, 10, 1041-1052 (1986).

6. T. C. Hoering, Organic Geochemistry, 5, 267-278, (1984).

7. R. M. Allen and J. B. VanderSande, Fuel, 3, 24-29 (1984). 


\title{
THE EFFECTS OF HYDROTHERMAL TREATMENT ON WYODAK COAL
}

\author{
David S. Ross, Albert S. Hirschon, Doris S. Tse, and Bock H. Loo \\ SRI International \\ Menlo Park, CA 94025
}

Keywords: hydrous pyrolysis, hydrothermal treatment, Wyodak

\section{INTRODUCTION}

There are a number of accounts of the treatment of coal with steam, including the recent work of Beinkowski et al., 1 Brandes and Graff, 2,3 and Kahn, et al. ${ }^{4}$ These efforts sought benefits to liquefaction and pyrolytic tar yields, and described changes in both the composition and the behavior of the coals. In other work Rozgonyi et al. described ash and sulfur reductions in steam-treated coal, 5 and some of our recent work with Illinois No. 6 coal in hot liquid water is described in a paper elsewhere in these preprints. ${ }^{6}$

The hydrothermal conditions used in these efforts are reminiscent of the hydrous pyrolysis studies conducted in research dealing with the accelerated maturation of oil shale. ${ }^{7,8}$ Source rocks are heated in liquid water at temperatures in the $300-350^{\circ} \mathrm{C}$ range, resulting in the net production of alkanes and other hydrocarbons, in contrast to the case for dry pyrolysis where olefins are produced. The claim that hydrous pyrolysis actually mimics the natural process has been questioned recently, 9,10 but the phenomenology is unquestioned.

The work described here is an attempt to bridge the two areas. We are seeking to understand the changes brought about in Wyodak coal by liquid water in the range $150-350^{\circ} \mathrm{C}$ in terms of its structure. We expect the results of this work to provide some insight into any benefits such treatment provides liquefaction and volatiles production.

\section{EXPERIMENTAL}

Our work was conducted with Wyodak samples from the Argonne Premium Coal Bank. In most cases the starting coal was dried in an oven at $60^{\circ} \mathrm{C} / 1 \mathrm{tor} / 20 \mathrm{hr}$, a pretreatment that resulted in a loss of water representing about $30 \%$ of the coal mass. In some runs the as received coal was used, and we found no difference in behavior following hydrothermal treatment. The as received coal was used as well in a control run where the treatment was conducted with no added water. In that case the water in the coal may have contributed to the subsequent pyrolytic behavior, as described below.

The hydrothermal treatment was conducted in a $45 \mathrm{ml}$ stainless steel reactor with a tightly fitting Pyrex insert. Sufficient water was used to assure in each case that a liquid phase was present at temperature, and the reactor was charged with 33-50 atm (500-750 psi) nitrogen (cold). The run temperatures $\left({ }^{\circ} \mathrm{C}\right)$ and respective vapor pressures of water (atm) were 150/4.6, 250/38, and 350/160. After treatment the coal/water mixture was centrifuged directly in the insert, most of the water removed by pipette and saved for later analysis, and the coal removed in an $\mathrm{N}_{2}$-purged glove bag. The remaining superficial water was then removed in a stream of dry nitrogen.

The bulk of the analysis was conducted by pyrolysis field ionization mass spectrometry (py-FIMS). The heating rate used throughout was $2.5^{\circ} \mathrm{C} / \mathrm{min}$, and spectra were recorded at nominally $30^{\circ}$ intervals from ambient to $500^{\circ} \mathrm{C}$. In some cases quantities of volatiles from the treated coal were transferred at $120^{\circ} \mathrm{C}$ via vacuum transfer to bulbs for analysis by conventional mass spectrometry. In addition to the parent-peak spectra, py-FIMS output included volatility data, and values for the weight average molecular weights $\left(\mathrm{M}_{\mathrm{w}}\right)$ of the fractions. 
Analysis of the water fractions were conducted by first saturating the aqueous phase with $\mathrm{NaCl}$, and then extracting with methylene chloride. The extracts were then analyzed by gas chromatography, and identification confirmed by comparison with authentic samples.

\section{BACKGROUND}

Bienkowski et al. reported on the abundance of alkylated phenols and dihydroxybenzenes both in the pyrolysis tars of Wyodak coal, and in the water collected following steam treatment. ${ }^{1}$ Kahn et al. similarly identified a large collection of phenols in the treatment water. ${ }^{2}$ These results are expected based on the lignin residues present in this rank of coal.11

There is also a wide range of biomarkers reported for the extracts of Wyodak coal in work by Baset, et al. who studied benzene/ethanol extracts and pyrolysates evolved directly from the heated coal. 12 The extracts included ferruginol and retene, and they sought but found no pristane. The presence of the<smiles>CC(C)c1cc2c(cc1O)[C@]1(C)CCCC(C)(C)C1CC2</smiles>

ferruginol<smiles>Cc1ccc2c(ccc3c(C)cccc32)c1</smiles>

retene<smiles>CC(C)CCCC(C)CCCC(C)CCCC(C)C</smiles>

pristane

corresponding olefin pristene in the pyrolysate, however, suggested that the alkane or a precursor was bound to the coal, and then released as the olefin when the coal was heated.

The geochemical $\mathrm{s}^{t}$ udies on oil shale could be related to these findings, with the account by Hoering of specific interest. ${ }^{8}$ In that work the treatment of preextracted Messel shale in liquid water at $330^{\circ} \mathrm{C} / 3$ days generated petroleum hydrocarbons including long chain normal alkanes, aromatics, and biomarkers. When $\mathrm{D}_{2} \mathrm{O}$ was used, deuterium was heavily incorporated into the hydrocarbons. Hoering's control results and the distributions of isotopic isomers essentially ruled out preexisting, trapped hydrocarbons, and the results suggested that the hydrocarbons were not merely freed, but rather generated in some manner by the water.

\section{RESULTS}

We conducted a number of experiments with hydrothermal treatments at $150^{\circ}$ and $250^{\circ} \mathrm{C}$, with the majority of the work at $350^{\circ} \mathrm{C}$. Analyses of the recovered coals included py-FIMS and simple analyses of recovered water and volatiles samples. 


\section{Recovered Water, Direct Volatiles Analyses, and Elemental Analysis}

As expected, analysis of the recovered water from $350^{\circ} \mathrm{C}$ treatment runs showed the presence of phenols and dihydroxybenzenes. The most prominent products were catechol $\left(\mathrm{O}-(\mathrm{OH})_{2} \mathrm{Ph}\right)$ and phenol in a ratio of about $2 / 1$. Other products found in smaller quantities were resorcinol $\left(\mathrm{m}-(\mathrm{OH})_{2} \mathrm{Ph}\right)$ and hydroquinone $\left(\mathrm{D}-(\mathrm{OH})_{2} \mathrm{Ph}\right)$, with the ratio catechol/(resorcinol + hydroquinone $)=6 / 1$.

The same materials were pulled from the coal heated to $120^{\circ} \mathrm{C}$ in a vacuum line transfer, and identified by conventional mass spectrometry. In this case phenol was the most prominent material; however we were surprised to find acetone as a major volatile product, present in quantities similar to those for phenol.* Smaller quantities of simple ketones including butanone and a pentanone were also identified. These findings are discussed further below.

The elemental analyses from the work at $350^{\circ} \mathrm{C}$ are presented in Table 1 . The \%-oxygen values are by direct $\mathrm{O}$-analysis. The final columns in the table show calculated compositions based on specific loss of the elements of $\mathrm{CO}_{2}$ and $\mathrm{H}_{2} \mathrm{O}$, and values for the net loss of $\mathrm{OH}$ are also shown for comparison. Clearly $\mathrm{CO}_{2}$ loss is not significant, and water loss fits rather well. Curiously loss of $\mathrm{OH}$ fits the measured values even better, although the accuracy of the measured values may not warrant our modeling the results to such a degree. The product coals from the $150^{\circ}$ and $250^{\circ} \mathrm{C}$ work showed no O-loss.

Thus at $350^{\circ} \mathrm{C}$ we see about a $30 \%$ loss of oxygen, but significantly the loss is independent of the presence of added water. Kahn et al recorded about a $20 \%$ O-loss for Wyodak coal with steam at 304$320^{\circ} \mathrm{C}$, and we have noted that about half the oxygen in Illinois No. 6 coal is lost in water $/ \mathrm{N}_{2}$ at $400^{\circ} \mathrm{C} .13$ The present results show that at least for Wyodak coal the loss is strictly thermally promoted and does not require added water. However it is notable that the loss of water in the hydrothermal case occurs at a partial pressure of water of $160 \mathrm{~atm}$. The process is thus highly irreversible, and obviously does not involve bound or sorbed molecular water. One candidate water source are coal clays, which dehydrate at elevated temperatures. ${ }^{14}$ However that process is reversible, and at any rate is very highly suppressed below around $475^{\circ} \mathrm{C}$ under just a few torr of water vapor. ${ }^{15}$

We conclude that the water loss must involve the dehydration specifically of chemically bound elements of water in the organic phase of the coal. The dehydration may be tied to the fact that catechol is a prominent thermal product. And as we have shown in other work, catechol thermally dehydrates and forms oligomers at $300^{\circ}-400^{\circ} \mathrm{C}$ in the presence of kaolinite, one of the clays in coal. We expect to develop a better understanding of this process in further work.

\section{Volatilities}

Several different py-FIMS measurements were made of separate samples of the as received coal on different days to establish the reproducibility of the method and the stability of the instrument, and the results of those runs (points) along with those for $150^{\circ}$ and $250^{\circ} \mathrm{C}$ treatments (curves) are presented in Figure 1. The data for the as received coal fall essentially upon one another, demonstrating a satisfactory precision. The similar alignment of the data from the treated coal shows that little change in the coal takes place at $150^{\circ}$, while some activity is seen at the $250^{\circ}$ level. The volatile fractions in these cases and in those below was consistently $25-30 \%$.

The shape of the curves for the as received coal demonstrates two regions of activity. Below $300^{\circ}-320^{\circ} \mathrm{C}$ the small quantities of preexisting volatile material in the coal are evaporated into the instrument. Then at higher temperatures pyrolytic fragmentation of the coal occurs, and products of that process are recorded. Thus for the as received coal and the $150^{\circ}$ sample, no more than about $10 \%$ of the ultimately volatile material emerges in the first region. For the $250^{\circ}$ treatment, since that temperature was below the point of substantial thermolysis, the increased volatiles for that run must be due specifically to the action of water in the treatment.

\footnotetext{
* The possibility of adventicious acetone was considered. However the prese. 1 ce of acetone solely in runs from the $350^{\circ} \mathrm{C}$ treatment confirmed its formation in the process.
} 
This point is demonstrated more clearly for the $350^{\circ}$ work in Figure 2. The figure presents the curves for $30 \mathrm{~min}$ runs at $350^{\circ} \mathrm{C}$ both with added water ( 2 runs) and without added water, with some data for the as received coal are shown again for comparison. In this case to assure no confusion from possible thermal effects from oven drying, the as received coal was used for the run with no water.

The effects tied specifically to the hydrothermal conditions are evident from the profiles. They are emphasized by comparing the \%-volatile values at an abscissa value of $350^{\circ} \mathrm{C}$, the temperature at which the coal was treated, and for the as received, no water, and hydrothermal samples the volatilities are respectively $22 \%, 37 \%$ and $52 \%$. The jump from 22 to $37 \%$ reflects a thermal effect that can be anticipated since the treatment temperature was in the pyrolysis range, although we cannot rule out some action by the water driven out of the coal. (Work with dried samples is in progress.) The remaining increase to 52\%, however, must be due specifically to the presence of water.

Recognizing that the treatment involves holding coal samples at temperature for $30 \mathrm{~min}$, and that the py-FIMS heating rate is $2.5^{\circ} \mathrm{C} / \mathrm{min}$, another useful comparison can be made over the interval $350^{\circ}$ to $-425^{\circ} \mathrm{C}$ (i.e. $350^{\circ} \mathrm{C}$ to $\sim\left[350^{\circ}+2.5 \times 30\right]$ ). The pertinent data are presented in Table 2 , which shows that the weight average molecular weights $(M)_{W}$ for the tars from the hydrothermally treated coal are consistently greater than those for both the as received and thermally heated samples, a result in turn consistent with the view that added water specifically affects the subsequent pyrolytic properties.

An effect is apparent as well from inspection of the Pyrex inserts after the runs. For the hydrothermal treatment they showed considerable quantities of tar deposited on the walls. For the thermal treatment case, however, the walls were clean, except for droplets of water which was driven from the coal during the treatment. Some insight into the these effects can be developed with inspection of the various FIMS spectra, with attention to the effects of treatment on individual compound classes.

\section{FIMS Spectra and Coal Tars}

Treatment at $350^{\circ} \mathrm{C}$. FIMS spectra are presented in Figure 3 for the as received coal and for the $350^{\circ}$ treatment both with and without water. Each spectrum is the accumulated signal for each sample up to a py-FIMS temperature of $300^{\circ} \mathrm{C}$, and the differences in volatilities shown in Figure 2 are evident here.

Specific effects of the addition of water can be gathered from the difference spectrum shown in Figure 4. The figure represents [hydrothermally treated] minus [thermally treated], and is derived from the respective spectra for the full volatiles fractions evolved to $500^{\circ} \mathrm{C}$. The data from the two runs have been normalized, so that the differences reflect changes in the compositions. Thus the addition of water shifts the thermolytic behavior of the coal so that the volatiles are richer in dihydroxybenzenes and a broad range of coal tar material at $\mathrm{m} / \mathrm{z}$ values $200-500 \mathrm{amu}$, and depleted in phenols.

Also very prominent in both spectra is $\mathrm{m} / \mathrm{z}=58$, identified as acetone by vacuum line isolation and analysis. The difference spectrum shows that its levels are elevated relatively in the pyrolysate from the thermally treated coal, probably due to its solubility in water. Other simple ketones in smaller quantities were also identified as noted above. We are not aware of accounts of acetone or other simple ketones as products of coal thermolysis, although such compounds are identified in wood tars and are derived from cellulose. ${ }^{16}$ This finding could reflect the presence cellulose residues in Wyodak coal, and we expect to look further into this matter in future studies.

The profiles for the generation of acetone, phenol and dihydroxybenzene as a function of temperature are shown in Figure 5. For the as received coal the activity is almost solely in the pyrolysis region, and dihydroxybenzene (most likely catechol) is the most prominent product, with its production peaking at around $400^{\circ} \mathrm{C}$. Both the thermal and hydrothermal treatments shift the production of all three materials to lower temperatures, but the presence of added water does not appear to affect the phenol and acetone release. The addition of water clearly affects dihydroxybenzene evolution, however, moving it to lower temperatures. 
The assignments in the figure are probably satisfactory to py-FIMS temperatures up to $300^{\circ} \mathrm{C}$, and for $\mathrm{m} / \mathrm{z}$ $=90$ and 110 perhaps all the way to $500^{\circ} \mathrm{C}$. However $\mathrm{m} / \mathrm{z}=58$ above $300^{\circ} \mathrm{C}$ probably represents butane rather than acetone, although as the figure sho' $s$ s the point is moot since it is not significant in that region. On the other hand it is prominent at lower temperatures for the thermally and hydrothermally treated coal, its peaking coinciding closely with that for phenol. Given that all three compounds are volatile, it is surprising that the maximum in their lower temperature evolution falls at around $140^{\circ} \mathrm{C}$. For the hydrothermally treated coal there is some immediate evolution which then declines, and we assign this behavior to some material fully released by the water, and thus simply "sitting" on coal and readily pumped into the FIMS instrument. However the delayed, common peaking temperature for much of the phenol, dihydroxybenzene, and acetone suggests that they are present together in a nonvolatile, complexed form generated in initial thermal or hydrothermal treatment. We expect to continue work in this system to develop a better understanding of the sources of these materials.

Treatment at $250^{\circ} \mathrm{C}$. Just as for the $350^{\circ}$ work, treatment at $250^{\circ} \mathrm{C}$ promoted the production of coal tar, albeit at a lower level. The fact that tar was produced with treatment at a temperature below the pyrolysis region is another reflection of the specific action of water in the treatment. However there were significant differences between the $350^{\circ}$ and $250^{\circ}$ results. First, as shown in Figure 6, the phenols and benzenediols for the treated coal emerge fully in the pyrolysis region, and no acetone is seen. In this regard the treated coal acts like the as received coal, and the result is not surprising since from the $350^{\circ}$ work we learned that the phenols and acetone were pyrolytically produced.

Second, several prominent peaks appear in the FIMS of the tars of the treated coal, but are present in neither the as received nor the $350^{\circ}$-treated coal. These compounds emerge at py-FIMS temperatures around $100^{\circ} \mathrm{C}$, with $\mathrm{m} / \mathrm{z}$ values corresponding to the parent masses of some biomarkers. They include peaks at 234, 268 and $270 \mathrm{amu}$, which correspond respectively to retene, pristane, and ferruginol. A prominent peak also appears a $\mathrm{m} / \mathrm{z}=252$, and we are aware of no corresponding biomarker.

We emphasize that while these parent masses correspond to the biomarkers, at present we have no additional information on the structures. However with this caveat, it appears that there is some hydrolytic release of biomarkers. The mechanism of that action is of interest, particularly in the case of hydrocarbons such as reterle and pristane which have no "handles" for the action of water. The question of the role of mineral matter in these processes must be raised, including aspects of coal structure which might provide substantial and widely ranging interaction between the organic and mineral components in coal.

\section{DISCUSSION}

Our accumulated evidence thus far shows that there are both water-independent and water-promoted modes of release of tars and specific compounds. Phenols and acetone are evolved thermally at temperatures above $300^{\circ} \mathrm{C}$, while hydrothermal conditions affect the dihydroxybenzene evolution. The question remains as to what features in the structure are responsible for this behavior. The production of acetone and other simpie ketones may reflect the presence of some cellulose-related residue in the coal.

The water-promoted evolution of tars and biomarkers seems similar to the observations from the hydrous pyrolysis studies of oil shale. For oil shale such chemistry probably involves interfacial chemistry at the boundary joining the organic and mineral surfaces. In the case of coal, Allen and VanderSande have estimated that ultrafine mineral matter in the organic phase may represent up to $15 \%$ of the total quantity of mineral material in coal, 17 and the distribution of such a fine mineral material throughout the organic phase would lead to a significant interfacial volume. Our results may thus mirror the existence of such a volume, and specific interfacial chemistry generating and/or liberating volatile materials.

Finally, a possible parallel between oil shale and coal structure leads to an interesting surmise regarding the distribution of heteroatom components in coal. The heteroatom-containing fractions of oil shale are concentrated at the mineral surfaces, ${ }^{18}$ presumably migrating over geologic time to acid/base sites in the clays. Were such a condition to exist in coal, we would then expect a nonrandom distribution of 
heteroatom components, localized at the mineral inclusions within the organic phase. Such a picture of coal is considerably different from the structures commonly considered, and could be significant to the processing coal.

\section{ACKNOWLEDGEMENT}

We acknowledge support of the US DOE on Contract No. DE-AC22-89PC89880. We also are pleased to acknowledge helpful discussions with R. Malhotra and D. McMillen of SRI, and T. Milne of SERI.

\section{REFERENCES}

1. P. R. Beinkowski, R. Narayan, R. A. Greenkorn, and K-C Chao, Ind. Eng. Chem. Res., 26, 202205 (1987).

2. S. D. Brandes and R. A. Graff, Am. Chem. Soc. Div. of Fuel Chemistry Preprints, 32 (3), 385-393 (1987).

3. R. A. Graff and S. D. Brandes, Energy and Fuels, 1, 84-88 (1987).

4. M. R. Kahn, W-Y. Chen and E. Suuberg, Energy and Fuels, 3, 223-230.

5. T. G. Rozgonyi, M. S. Mohan, R. A. Zingaro, and J. H. Zoeller, Jr., in Proceedings of the 2nd International Conference on Processing and Utilization of High Sulfur Coals, Y. Chugh, R. Caudle, C. Muchmore, and A. Sinha, Dds. (Elsevier, New York, 1988)

6. David S. Ross and Albert Hirschon, Am. Chem. Soc. Div. of Fuel Chemistry Preprints, 35, 000-000 (1990).

7. a) M. D. Lewan, J. C. Winters, and J. H. McDonald, Science, 203, 897-899 (1979)..

8. T. C. Hoering, Organic Geochemistry, 5, 267-278, (1984).

9. M. Monthioux,.P. Laniais, and J-C. Monin, Organic Geochemistry, 8, 275-292 (1985).

10. E. Tannenbaum and I. R. Kaplan, Nature, 317, 708-709 (1985)

11. P. G. Hatcher, H. E. Lerch, III, R. K. Korta, and T. V. Verhayen, Fuel, 67, 1069-1075 (1988).

12. Z. H. Baset, R. J. Pancirov, and T. R. Ashe in Adv. Org. Geochem.1979, A. G. Douglas and J. Maxwell, eds., Pergamon Press, Oxford, pp. 619-630.

13. D. S. Ross, T. K. Green, R. Mansani, and G. P. Hum, Energy and Fuels, 1, 292-294, (1987).

14. J. Unsworth, C. Fowler, N. Heard, V. Weldon and V. McBrierty, Fuel, 67, 1111-1119, (1988).

15. R. L. Stone, J. Am. Ceram. Soc., 35, 96-99, (1952); G. W. Brindley and J. Jemaitre in Chemistry of Clays and Clay Minerals, A. Newman, ed., Longman Scientific and Technical, London, 1987, pp. 327-329

16. R. J. Evans and T. A. Milne, Energy and Fuels, 1 (2), 123-137, (1987).

17. R. M. Allen and J. B. VanderSande, Fuel, 3, 24-29 (1984).

18. J. J. McKay and R. S. Blanche, Liquid Fuels Technology, 3 (4), 489-521, (1985). 


\section{Table 1}

\section{Analyses of As Received and $350^{\circ} \mathrm{C}$-Treated \\ Wyodak Coal}

$$
\text { Starting Coal Treated Coal Calculated For Loss Ofa }
$$

With Water No Water $\quad \mathrm{CO}_{2} \quad \mathrm{H}_{2} \mathrm{O} \quad$ "OH"

\begin{tabular}{|c|c|c|c|c|c|}
\hline$\% \mathrm{C}$ & $\begin{array}{l}66.47 \\
67.60\end{array}$ & 71.56 & 72.17 & 70.45 & 71.67 \\
\hline$\% \mathrm{H}$ & $\begin{array}{l}5.10 \\
5.02\end{array}$ & 4.89 & 4.99 & 5.62 & 4.61 \\
\hline \%N & $\begin{array}{l}0.85 \\
0.86\end{array}$ & 0.95 & 0.94 & 0.93 & 0.91 \\
\hline$\% 0$ & $\begin{array}{l}20.92 \\
21.63\end{array}$ & 14.92 & 15.88 & 15.48 & 15.49 \\
\hline & $\begin{array}{l}8.23 \\
8.58\end{array}$ & 9.04 & 9.08 & 9.08 & 8.87 \\
\hline
\end{tabular}

a. Calculated for loss of elements of $\mathrm{CO}_{2}, \mathrm{H}_{2} \mathrm{O}$ and $\mathrm{OH}$ from the starting coal, to match a final O-content of 15.4-15.5\%.

Table 2

Weight Average Molecular Weights of Tars from As Received,Thermally Treated, and Hydrothermally Treated Wyodak Coal

$\begin{array}{ccc}\begin{array}{c}\text { py-FIMS Temperature } \\ \text { Interval }\left({ }^{\circ} \mathrm{C}\right)\end{array} & \overline{\mathrm{M}}_{\mathrm{w}} \\ & \text { Sample } & \\ 332-359 & & 458 \\ & \text { As received } & 434 \\ & \text { Thermal } & 518 \\ 362-389 & \text { Hydrothermal } & 455 \\ & \text { As received } & 449 \\ & \text { Thermal } & 516 \\ 392-419 & \text { Hydrothermal } & 431 \\ & \text { As received } & 427 \\ & \text { Thermai } & 507 \\ 422-449 & \text { Hydrothermal } & 366 \\ & & 356 \\ & \text { As receive } & 403\end{array}$

a. Thermal and hydrothermal samples heated at $350^{\circ} \mathrm{C} / 30 \mathrm{~min}$. 


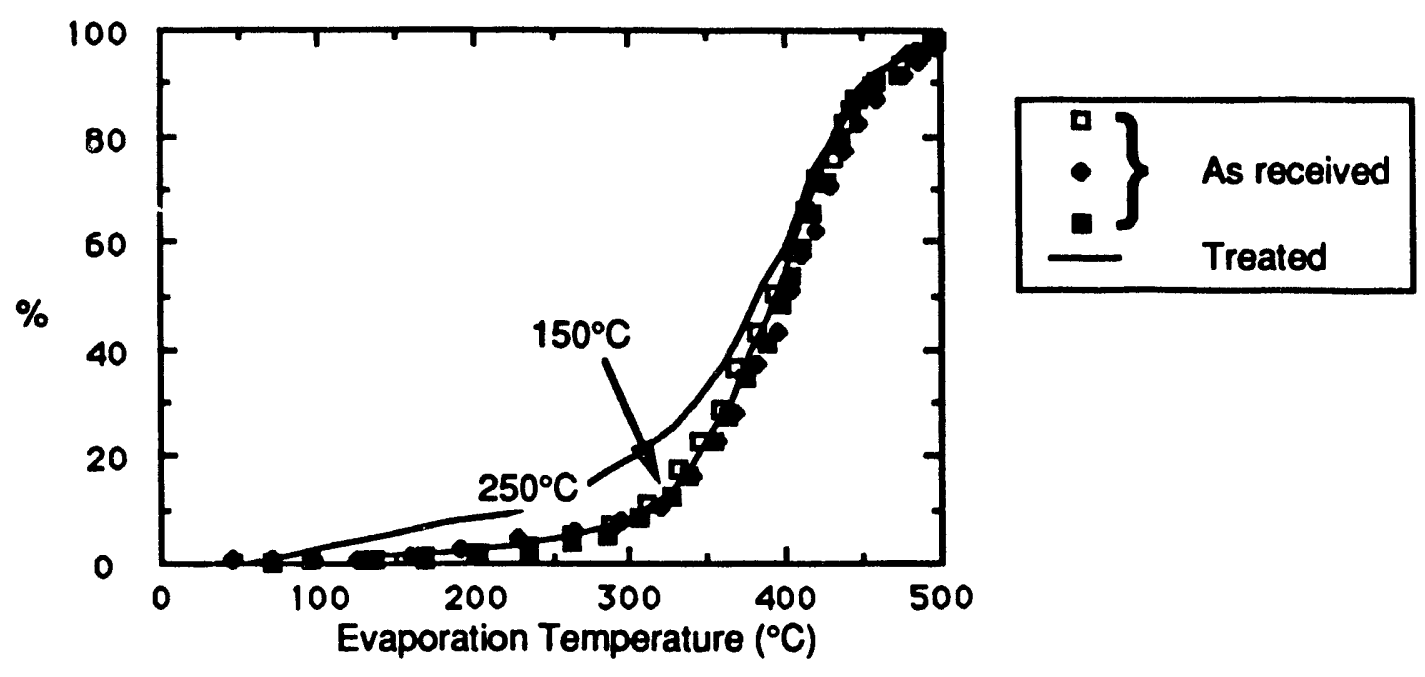

Figure 1. Evaporation curves for the as received coal and the $150^{\circ}$ and $250^{\circ} \mathrm{C}$ coal products.
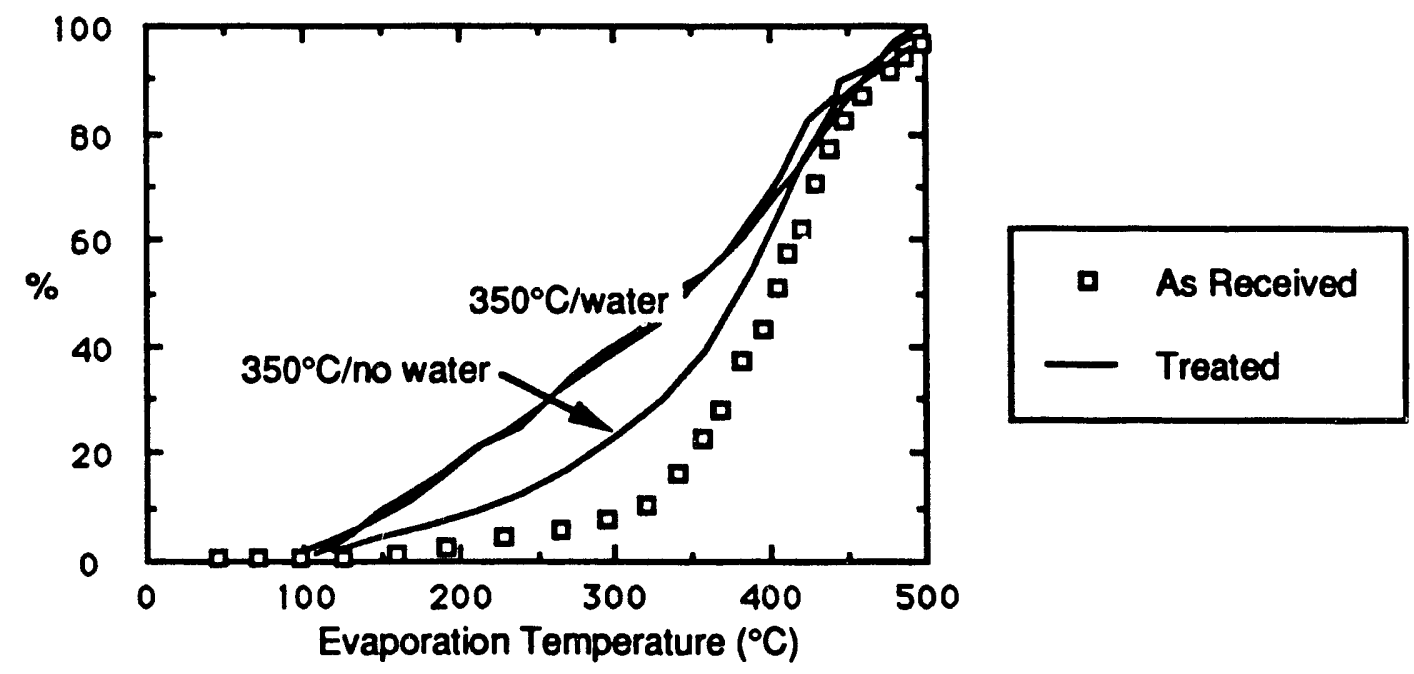

Figure 2. Evaporation curves for the as received coal, and products from $350^{\circ} \mathrm{C}$ runs both with ( 2 runs) and without water. 


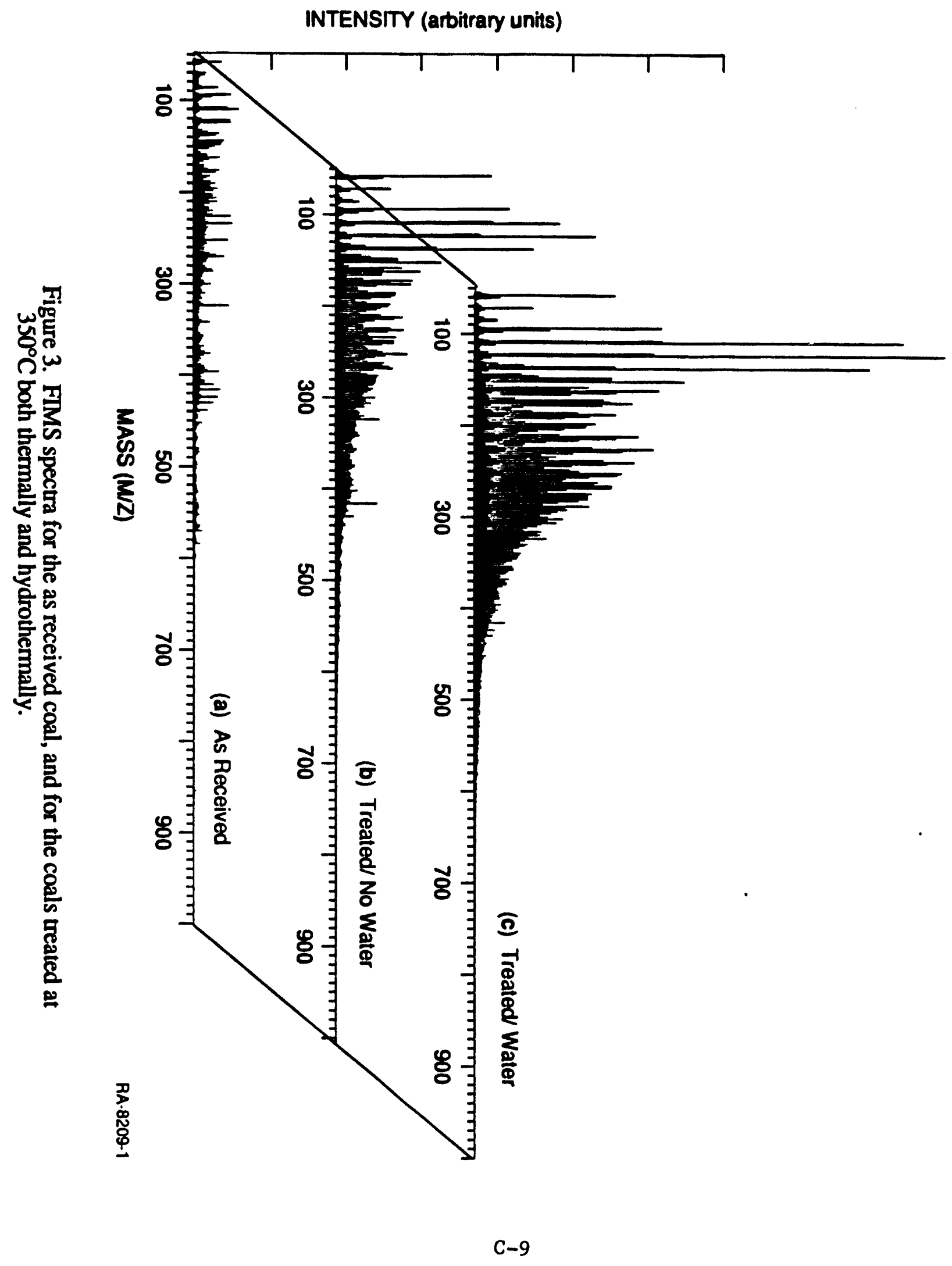


\% DIFF TOTAL ION INIENSITY

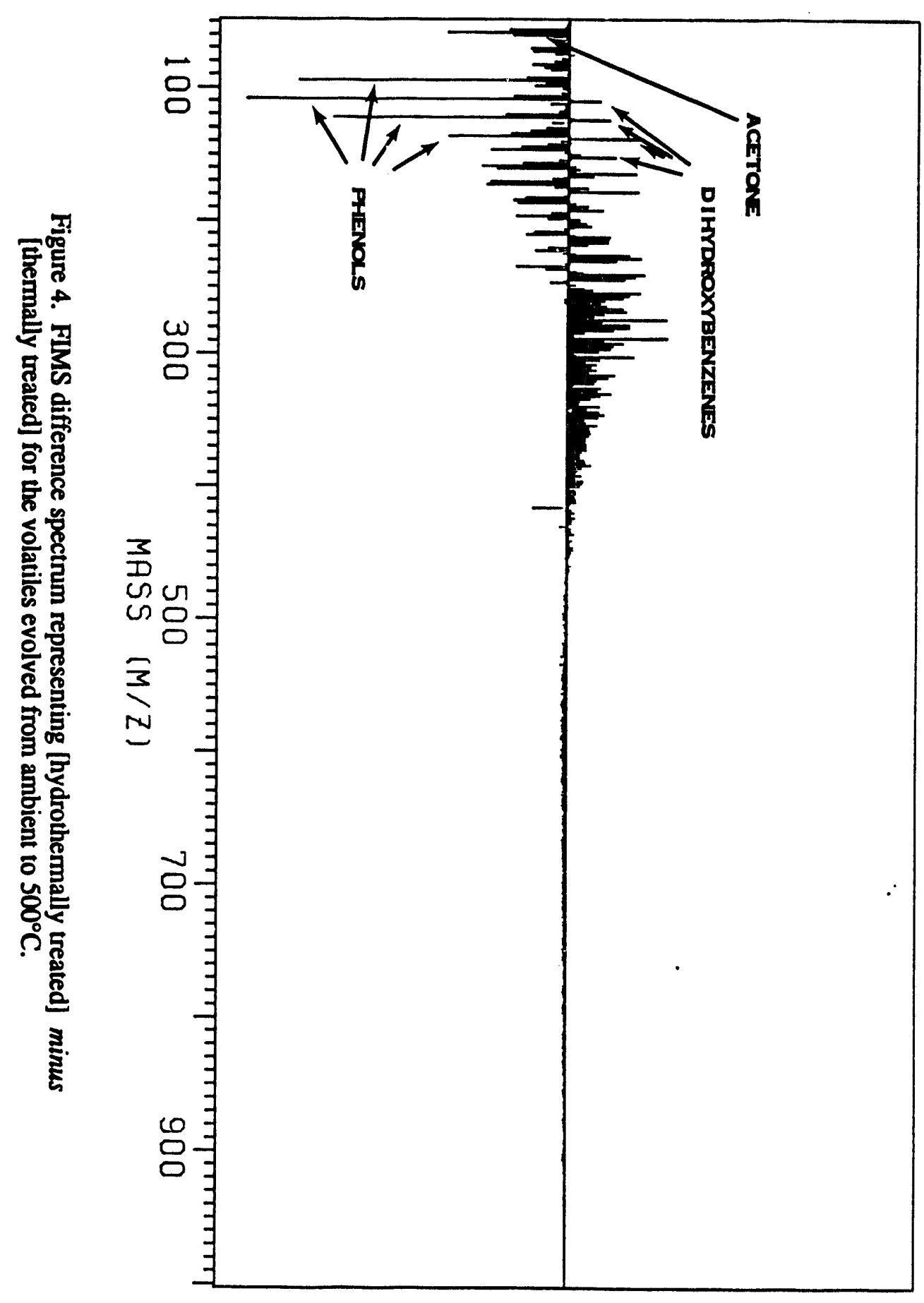

C-10 

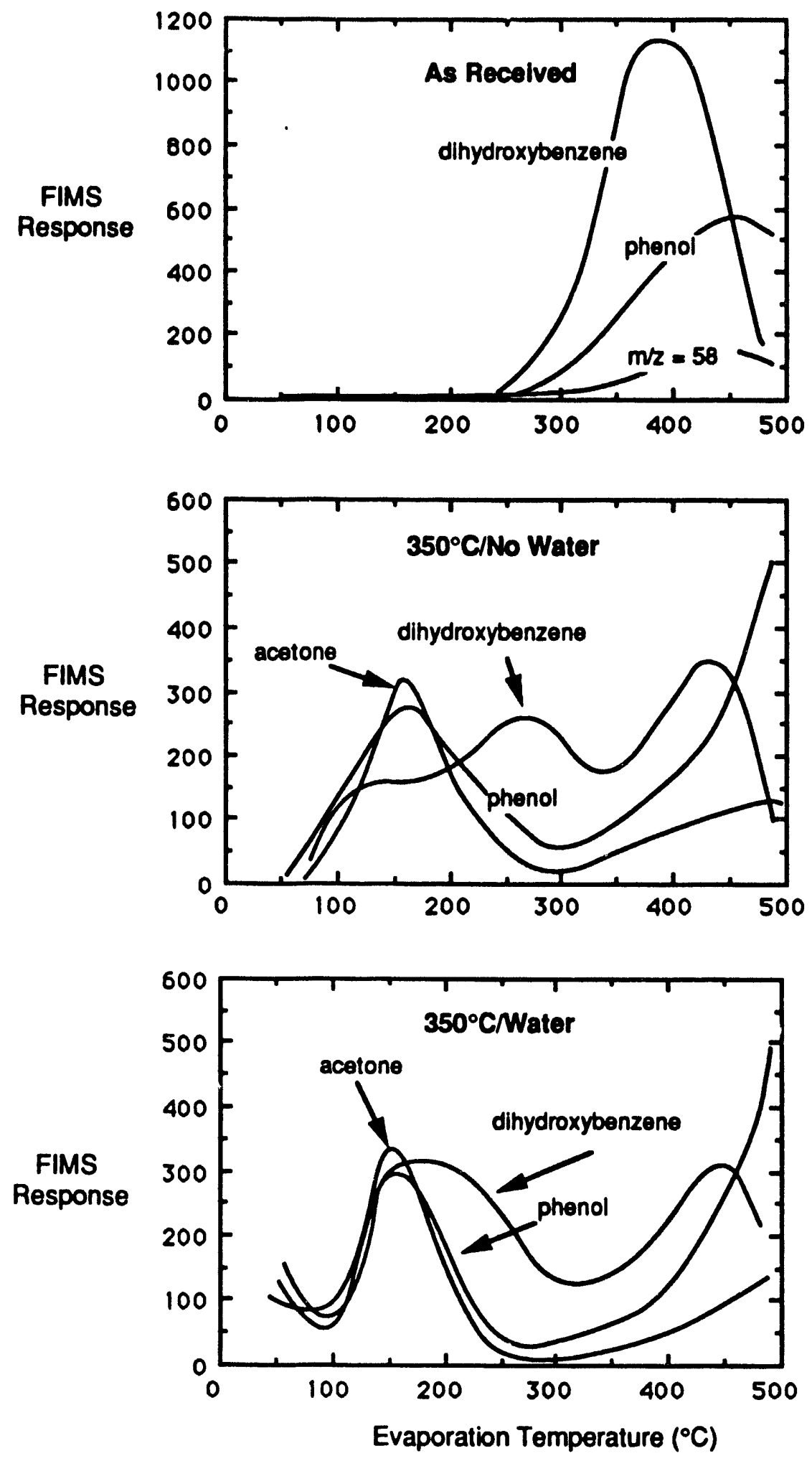

Figure 5. FIMS-derived profiles for acetone, phenol and dihydroxybenzene for runs at $350^{\circ} \mathrm{C}$. The dihydroxybenzene is primarily catechol. 

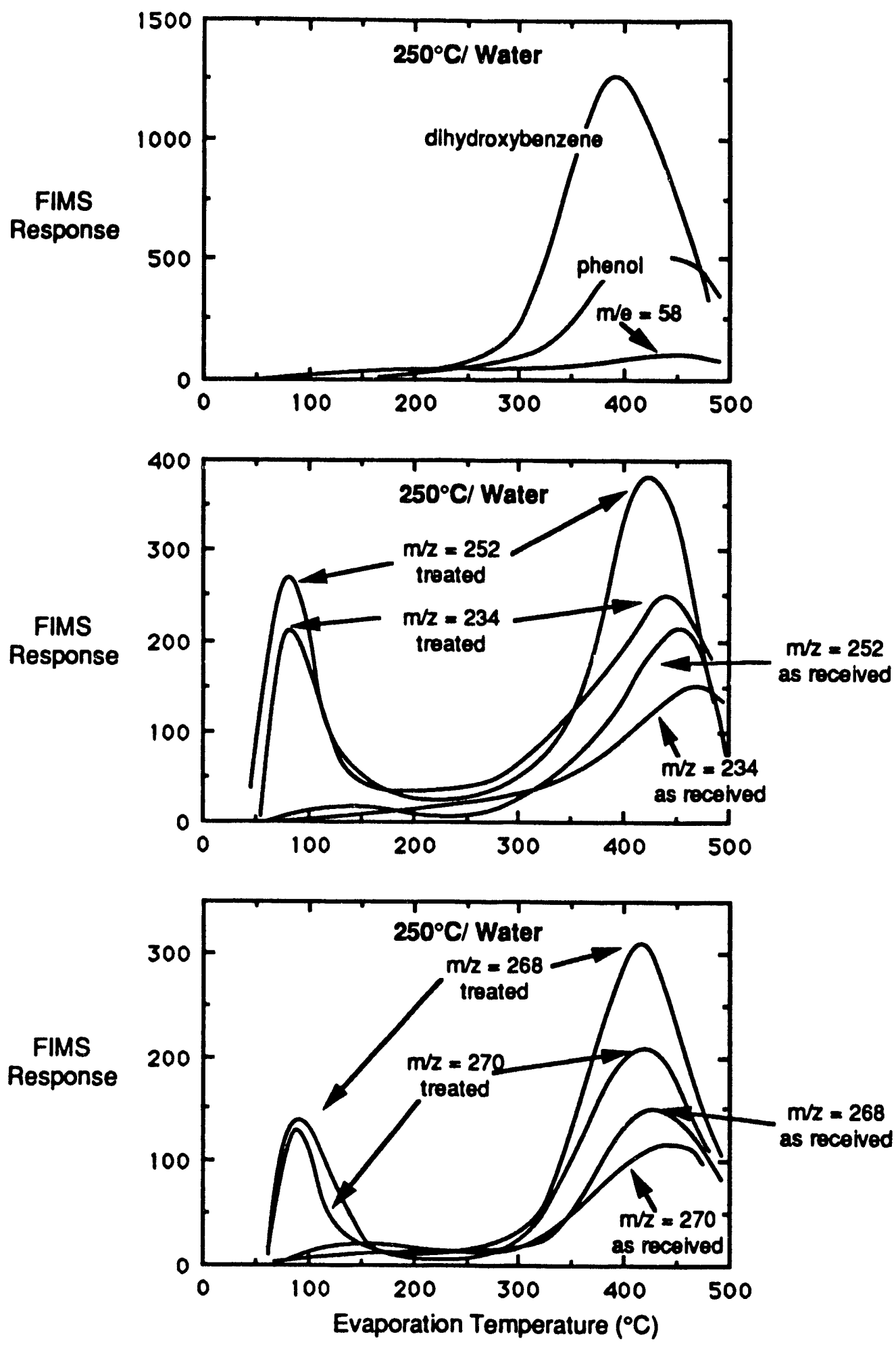

Figure 6. FIMS-derived profiles for several products from runs at $250^{\circ} \mathrm{C}$. The $\mathrm{m} / \mathrm{z}$ values at 234,268 , and 270 correspond to the parent masses for retene, pristane and ferruginol respectively. 


\title{
EFFECT OF HYDROTHERMAL PRETREATMENT FOR COPROCESSING
}

Doris S. Tse, Albert S. Hirschon, Ripudaman Malhotra, Donald F. McMillen, and David S. Koss

Chemistry Laboratory

SRI International Menlo Park, California 94025-3403

KEYWORDS: Water, Pretreatment, Coprocessing

\begin{abstract}
We report here effects of hydrothermal pretreatment on coprocessing of three different coals from the Argonne Premium Coal Sample Program. Aqueous pretreatment has resulted in a marked beneficial effect in terms of conversion to hexane solubles for Wyodak subbituminous coal and Zap lignite. The effect on the Illinois No. $6 \mathrm{coal}$ was negligible to slightly detrimental. Hydrothermal pretreatment of Wyodak subbituminous coal (1 part) at $250^{\circ}, 300^{\circ}$, and $350^{\circ} \mathrm{C}$ for 30 min followed by coprocessing with Maya ATB ( 2 parts) at $425^{\circ} \mathrm{C}$ for $1 \mathrm{~h}$, resulted in $26.0 \%$, $23.5 \%$, and $23.5 \%$ hexane insolubles based on total feed. Without hydrothermal pretreatment, $31.5 \%$ of the feed ended up as hexane insolubles. Use of a donor solvent, tetralin, in place of water during pretreatment produced $27.5 \%$ hexane insolubles, and thus was not as effective as hydrothermal pretreatment for the Wyodak coal. Coupling of phenolic constituents and the effect of water in minimizing such retrogressive reactions provide a possible explanation of these results Support for this hypothesis was found in model compound studies with catechol. We observed that while coupling of catechol on kaolin proceeds very rapidly such that after $3 \mathrm{~h}$ at $350^{\circ} \mathrm{C}$ only $38 \%$ of the catechol was recovered, addition of water dramatically mitigated the coupling, with $96 \%$ recovery.
\end{abstract}

\section{INTRODUCTION}

The impact of water on coal conversion under different process conditions has been a subject of interest and controversy for some time. Recent studies have shown that mild hydrothermal treatment of an Illinois No. 6 coal substantially enhances conversion into soluble products. For instance the convertibility of an Illinois No. 6 coal into toluene-soluble products increased from $\sim 35 \%$ to almost $70 \%$ when the coal was treated for 30 minutes with water at $250^{\circ} \mathrm{C}$ under nitrogen, and then subjected to conversion in CO/water systems.(1) Similar favorable effects of mild hydrothermal pretreatment have also been reported for conversions in pyrene (2) and for rapid hydropyrolysis. $(3,4)$ However, the benefits of water pretreatment are clearly not general in that they are not observed for all coals under al! combinations of pretreatment and subsequent processing conditions.

We present here results from a study we undertook to determine whether the beneficial effects of mild hydrothermal pretreatment can be exploited in the context of coprocessing. The objectives of this study were to explore the range of benefits, with respect to coal type, temperature of pretreatment, and the manner of water removal. In a parallel study, we have examined the impact of water on clay-catalyzed coupling of phenolics. Together, the two studies strongly indicate that the beneficial impact of water is due to the suppression of retrogressive coupling reactions. 


\section{EXPERIMENTAL}

The coals used in this study were Wyodak-Anderson seam subbituminous coal, Illinois No. 6 seam high volatile bituminous coal, and Beulah-Zap seam North Dakota lignite; all coals were obtained from the Argonne premium coal bank and used as received. To minimize exposure to air and the time between pretreatment and coprocessing, both the steps were conducted in the same microautoclave. The reactor ( $43 \mathrm{~mL}$ ) was charged with approximately $2.25 \mathrm{~g}$ of the coal and subjected to pretreatment conditions. Aqueous pretreatment was conducted at $250^{\circ}, 300^{\circ}$, or $350^{\circ} \mathrm{C}$ for $0.5 \mathrm{~h}$. After cooling, the excess water was pipetted out. Approximately $4.5 \mathrm{~g}$ of Maya ATB was added to the reactor, which was then filled with 1200 psig of hydrogen (cold). The reactor was shaken at $425^{\circ} \mathrm{C}$ for $1 \mathrm{~h}$ in a fluidized sandbath. Before opening the reactor, it was cooled in dry ice to prevent volatiles from escaping. Conversion to hexane solubles was the principal diagnostic used in this study, although other parameters such as THF-solubles, elemental composition, and FIMS-volatility were also determined for selected cases.

\section{RESULTS AND DISCUSSION}

Table 1 presents data from the coprocessing studies with Argonne premium samples of Wyodak coal and Maya ATB for a variety of pretreatment conditions. Experiment 1 in Table 1 gives conversion of Maya alone with no coal added and Experiment 2 gives the result for zoprocessing without any pretreatment. These entries represent base-line values to be used for determining the effect of various pretreatments shown in subsequent lines. Using the baseline conversion of Maya alone, we can determine the theoretical conversions of coal assuming that there is no interaction between the coal and and $\mathrm{r}$;sid. For instance, $18 \%$ by weight of hexane insoluble (HI) material was obiained after treating Maya under these thermal coprocessing conditions. If coal were added (in a ratio of 1 part coal to 2 parts Maya), then we would have obtained a yield of $12 \%$ if all of the coal had been converted to hexane soluble material. In contrast, if none of the coal had been converted, a value of $45 \%$ insoluble material would have been obtained. As shown in the table the results ranged from 22 to $34 \%$ hexane insoluble material, indicating that a significant portion of the coal had been converted.

\section{Effect of Pretreatment Conditions on Coprocessing of Wyodak and Maya ATB}

From the data in Table 1 we can immediately see that there is a marked beneficial impact of hydrothermal pretreatment with the yield of hexane-insolubles being reduced from $32 \%$ without pretreatment to $26 \%$ with pretreatment at $250^{\circ} \mathrm{C}$ (Experiments 3 and 4). Hydothermal pretreatment at $300^{\circ} \mathrm{C}$ further reduces hexane-insolubles yield to $24 \%$. Increasing the pretreatment temperature to $350^{\circ} \mathrm{C}$ results in no further benefit in terms of conversion to hexane-solubles. The additional conversion is not merely due to the extra heating that pretreatment provides. Dry heating of coal for $30 \mathrm{~min}$ at $350^{\circ} \mathrm{C}$ prior to coprocessing is in fact deleterious and results in $34 \%$ hexaneinsolubles. Even thermal pretreatment in tetralin, a donor solvent, is not as beneficial as hydrothermal pretreatment.

Baldwin et al. have shown that mild pretreatment treatment of several coals with with acidic alcohol solutiors results in enhanced conversion during subsequent coprocessing.(5) The premise of their work was that the pretreatment alkylates the coals thus preventing the phenolic and carboxylic groups from undergoing retrogressive reactions and lowering the yields. However, another possibility is that the pretreatment actually dewatered the coal, and the removal of water under mild conditions aided in the enhanced conversions. To test this hypothesis we used acetone which is also completely miscible with water, but which cannot alkylate hydroxyls. However, this treatment was somewhat deleterious and resulted in a slight increase in hexane-insolubles: $34 \%$ compared to the base line case of $33 \%$.

To determine if the pretreatment effect was limited to the coal, we treated the Maya ATB at $350^{\circ} \mathrm{C}$ in water. 'The water was removed, and Maya ATB was then subjected to treatment at $425^{\circ} \mathrm{C}$ in nitrogen (Expenivent 15) and in hydrogen (Experiment 16). In both cases the conversion was no different from that of no pretreatment. The fact that the HI yields under nitrogen and hydrogen for pure Maya are thie same is interesting, and suggests that perhaps the upgrading of the Maya is 
primarily a disproportionation reaction, where the hydrogen utilized for the upgrading comes

directly from the Maya ATB itself. This conclusion is in concert with the findings of Savage et al., (6) and Khorasheh et al.(7) who have reported that presence of hydrogen does not increase the yield of the distillates (which is often equated to hexane-solubles) under thermal and catalytic
processing of resids and gas oils, although it reduces coke formation.

\section{Effect of Coal Rank on Hydrothermal Pretreatment}

Table 2 presents data from the coprocessing studies with Argonne premium samples of Wyodak, Illinois No. 6, and North Dakota coals and lignite. Although bituminous coals are No. 6 coals without pretreatted than subbituminous coals, coprocessing of Wyodak and Ilinois hexane-insoluble material. enhancement of conversion, no ver, although the pretreatment of Wyodak gave a significant pretreatment of the lignite at $350^{\circ} \mathrm{C}$ was moderately benefial 6 coal was observed. Hydrothermal had optimized the pretreatment conditions using the Weneficial. It should be remembered that we assume that these conditions are optimal for othe Wyodak coal; and a priori have no reason to pronounced effect with a lower temperature other coals as well. The lignite may show a more show that the beneficial effects of and that other low rank coals also hydrothermal pretreatment are not specific to the Wyodak coal

\section{Possible Chemical Basis for Hydrothermal Pretreatment}

Various factors could explain the phenomenon of hydrothermal pretreacment and how it relates to the ultimate convertibility of coal. One possibility is that morphologogical changes affect mass transfer rates because the water contact increases pore volume and therefore opens the coal structure for subsequent conversions. However, other, more chemical explanations must also be low rank coals, which have relatively largethermal pretreatment was generally more pronounced for phenols are particularly prone to coupling amount of dihydric phenols, and because dihydric interactions by use of model phenol systems reactions, we investigated the effects of mineral/organic such as montmorillonite and kaolinite. In previous work we have shown that unless H-donor
solvents are present, phenolics such as catechol and resol (8). Trewhella et al., have also reported that and resorcinol undergo rapid coupling reactions significantly reduces the polymerization of the presence of hydrogen donors such as tetralin

We conducted a series of experiments in which catechol was heated in a sealed quartz ampoule in the presence of kaolin, a common clay mineral found in coals, and in the presence or absence of water or tetralin. Under the experimental conditions a substantial amount of catechol was converted to polymeric materials and not recovered. The product mixture was analyzed by GCMS to determine the amount of unconverted catechol and the small yields of phenol. Table 3 presents data on the self-coupling reactions of catechol in the temperature range from $300^{\circ}$ to amount of the catechol underwent kaolin, tetralin, and water. As shown in this table, only a small $\mathrm{h}$ (Experiment 1). It remained essent condensation reactions when heated by itself to $400^{\circ} \mathrm{C}$ for 1 material unaccounted for. Reaction at 35 as catechol $(75 \%)$ or phenol $(18 \%)$ with only $7 \%$ of products. However addition of kaolin mark (Experiment 4) results in even less of coupling $3 \mathrm{~h}$ at $350^{\circ} \mathrm{C}$ a mixture of catechol and kaolin (y accelerated coupling reactions. For instance, after catechol (and $4 \%$ phenol), compared to $92 \%$ anperiment 5 ) contains only $46 \%$ of the original of water, on the other hand, results in inhibition o these no clay added (Experiment 4 ). Addition water was added to the mixture, and $89 \%$ of the catechol coupling reactions. In Experiment 6 formed. Analogous effects of clay and water werechol was recovered, and $1 \%$ phenol was coupling of catechol with only $2 \%$ of the cater were observed at $400^{\circ} \mathrm{C}$. Addition of clay promotes presence of water, $84 \%$ was recovered (Experimerit 3). suggest that pretreatments and/or conversions in the 3 ). These results are very interesting, and formation by phenols of this type and lead to largir yield and/or a better quality produce crosslink 


\section{CONCLUSIONS}

We have shown here that hydrothermal pretreatment of low rank coals enhances conversion to hexane-solubles during subsequent coprocessing. We further showed that for the Wyodak coal, the benefit increased from an increase in the pretreatment temperature from $250^{\circ}$ to $300^{\circ} \mathrm{C}$, but no additional benefits were derived by further increase of temf srature to $300^{\circ} \mathrm{C}$. Dry thermal pretreatment is deterimental and even thermal pretreatment in donor solvents is not as effective as aqueous pretreatment. We, suspect that some of the benefits seen here evolve from changes brought about in clay-promoted retrogressive condensation chemistry. In a small study conducted to understand this phenomena we have shown that water markedly attenuates the clay-catalyzed coupling of phenolics.

Acknowledgment: Support for this work by the US Department of Energy under Contract No. DE-AC22-88PC88802 is gratefully acknowledged.

\section{REFERENCES}

1. A. S. Hirschon, D. S. Ross, L. L. Ackerman, "Low Severity Conversion of Activated Coal," SRI Quarterly Report, DOE/PC/79936-4 (October 1988).

2. I. Mochida, K. Iwamoto, T. Tahara, Y. Korai, H. Fujitsu, K. Takeshita, Fuel, 1982, 61, 603.

3. R. A. Graff, S. D. Brandes, Energy and Fuels, 1987, 1, 84-88.

4. P. Bienkowski, R. Narayan, R. Greenkorn, K-C Chao, Ind. Eng. Chem. Res., 1987, 26, 202.

5. R. L. Miller, M. E. Armstrong, R. M. Baldwin, ACS Div. Fuel Chem. Prep. 198934 (3), 873-880.

6. P. E. Savage, M. T. Klein, S. G Kukes, Energy and Fuels, 1988, 2, 619.

7. F. Khorasheh, H. A. Rangwala, M. R. Gray, I. G. Dalla Lana, Energy and Fuels, 1989, 3, 716.

8. D. F. McMillen, S.-J. Chang, S. E. Nigenda, and R. Malhotra, ACS Div. Fuel Chem. Prep. $1985,30(4), 414$.

9. M. J. Trewhella, A. Grint, Fuel 1988, 67, 1135. 
Table 1

COAL CONVERSION FROM COPROCESSING MAYA ATB AND WYODAK COAL IN MICROAUTOCLAVEa

\begin{tabular}{|c|c|c|c|}
\hline Experiment & Pretreatment ${ }^{b}$ & $\underset{(w t \%)}{H I}$ & $\begin{array}{c}\text { Coal } \\
\text { Conversion } b\end{array}$ \\
\hline 1 & Maya (no coal) & 18 & -- \\
\hline 2 & None & 32 & 40 \\
\hline $\begin{array}{l}3 \\
4\end{array}$ & $\begin{array}{l}250^{\circ} \mathrm{C} \\
250^{\circ} \mathrm{C}\end{array}$ & $\begin{array}{l}26 \\
27\end{array}$ & $\begin{array}{l}53 \\
53\end{array}$ \\
\hline $\begin{array}{l}5 \\
6\end{array}$ & $\begin{array}{l}300^{\circ} \mathrm{C} \\
300^{\circ} \mathrm{C}\end{array}$ & $\begin{array}{l}23 \\
24\end{array}$ & $\begin{array}{l}66 \\
63\end{array}$ \\
\hline $\begin{array}{l}7 \\
8\end{array}$ & $\begin{array}{l}350^{\circ} \mathrm{C} \\
350^{\circ} \mathrm{C}\end{array}$ & $\begin{array}{l}22 \\
25\end{array}$ & $\begin{array}{l}69 \\
60\end{array}$ \\
\hline $\begin{array}{r}9 \\
10\end{array}$ & $\begin{array}{l}\text { Thermal } 350^{\circ} \mathrm{C} \\
\text { Thermal } 350^{\circ} \mathrm{C}\end{array}$ & $\begin{array}{l}34 \\
34\end{array}$ & $\begin{array}{l}33 \\
33\end{array}$ \\
\hline $\begin{array}{l}11 \\
12\end{array}$ & $\begin{array}{l}\text { Vac Dried } 56^{\circ} \mathrm{C} \\
\text { Acetone Dried }\end{array}$ & $\begin{array}{l}34 \\
33\end{array}$ & $\begin{array}{l}33 \\
36\end{array}$ \\
\hline $\begin{array}{l}13 \\
14\end{array}$ & $\begin{array}{l}\text { Tetralin } 350^{\circ} \mathrm{C} \\
\text { Tetralin } 350^{\circ} \mathrm{C}\end{array}$ & $\begin{array}{l}28 \\
27\end{array}$ & $\begin{array}{l}52 \\
55\end{array}$ \\
\hline 15 & Maya (no coal, 350 pret) & 20 & -- \\
\hline 16 & Maya (no coal, 350 pret) & 23 & -. \\
\hline
\end{tabular}


Table 2

\section{COPROCESSING OF COALS OF DIFFERENT RANK WITH MAYA ATB IN MICROAUTOCLAVEa}

\begin{tabular}{|c|c|c|c|c|}
\hline Experiment & Coal & \multirow{2}{*}{$\begin{array}{c}\text { Pretreatment } \\
\text { None }\end{array}$} & \multirow{2}{*}{$\begin{array}{c}\begin{array}{l}\text { Hexane } \\
\text { Insoluble }\end{array} \\
18\end{array}$} & \multirow{2}{*}{$\begin{array}{l}\begin{array}{l}\text { Coal } \\
\text { Conversion }\end{array} \\
--\end{array}$} \\
\hline 1 & None & & & \\
\hline $\begin{array}{l}2 \\
3 \\
4\end{array}$ & $\begin{array}{l}\text { Wyodak } \\
\text { Wyodak } \\
\text { Wyodak }\end{array}$ & $\begin{array}{l}\text { None } \\
350^{\circ} \mathrm{C} \\
350^{\circ} \mathrm{C}\end{array}$ & $\begin{array}{l}32 \\
22 \\
25\end{array}$ & $\begin{array}{l}40 \\
69 \\
61\end{array}$ \\
\hline $\begin{array}{l}5 \\
6\end{array}$ & $\begin{array}{l}\text { Illinois No. } 6 \\
\text { Illinois No. } 6\end{array}$ & $\begin{array}{l}\text { None } \\
350^{\circ} \mathrm{C}\end{array}$ & $\begin{array}{l}34 \\
35\end{array}$ & $\begin{array}{l}33 \\
30\end{array}$ \\
\hline $\begin{array}{l}7 \\
8\end{array}$ & $\begin{array}{l}\text { Lignite } \\
\text { Lignite }\end{array}$ & $\begin{array}{l}\text { None } \\
350^{\circ} \mathrm{C}\end{array}$ & $\begin{array}{l}28 \\
24\end{array}$ & $\begin{array}{l}52 \\
64\end{array}$ \\
\hline
\end{tabular}

a. Reactions of coal and Maya ATB at $425^{\circ} \mathrm{C}$ for $1 \mathrm{~h}$ at and $1200 \mathrm{psi} \mathrm{H}_{2}$.

b. Coal conversion calculated assuming that the insoluble material from the Maya remains the same during the coprocessing experiment.

Table 3.

\section{EFFECT OF WATER ON CLAY-CATALYZED COUPLING REACTIONS OF} CATECHOL

\begin{tabular}{|c|c|c|c|c|c|c|}
\hline \multirow[b]{2}{*}{ Run } & \multirow[b]{2}{*}{ Description } & \multirow[b]{2}{*}{$\operatorname{Temp}\left({ }^{\circ} \mathrm{C}\right)$} & \multirow[b]{2}{*}{ Time (h) } & \multicolumn{3}{|c|}{ Mass Balance (Mol\%) } \\
\hline & & & & Catechol & Phenol & Remainder \\
\hline 1 & Catechol & 400 & 1 & 75 & 18 & 7 \\
\hline 2 & $\begin{array}{l}\text { Catechol/ } \\
\text { Kaolin }\end{array}$ & 400 & 1 & 2 & 0.2 & 98 \\
\hline 3 & $\begin{array}{l}\text { Catechol/ } \\
\text { Kaolin/water }\end{array}$ & 400 & 1 & 84 & 3 & 13 \\
\hline 4 & Catechol & 350 & 3 & 92 & 1 & 7 \\
\hline 5 & $\begin{array}{l}\text { Catechol/ } \\
\text { Kaolin }\end{array}$ & 350 & 3 & 38 & 4 & 52 \\
\hline 6 & $\begin{array}{l}\text { Catechol/ } \\
\text { Kaolin/water }\end{array}$ & 350 & 3 & 89 & 1 & 10 \\
\hline 7 & $\begin{array}{l}\text { Catechol/ } \\
\text { Kaolin }\end{array}$ & 300 & 5 & 83 & 8 & 9 \\
\hline 8 & $\begin{array}{l}\text { Catechol/ } \\
\text { Kaolin/water }\end{array}$ & 300 & 5 & 99 & 0 & 0 \\
\hline
\end{tabular}




\title{
CLEAVAGE OF BENZYLAROMATICS AND THEIR RELEVANCE TO COAL CONVERSION
}

\author{
D. F. McMillen, R. Malhotra, and D. S. Tse \\ Chemical Kinetics Department, SRI International, Menlo Park, California 94025.
}

KEYWORDS: Mechanism, Liquefaction, Hydrogen-transfer, RHT, Bond-Cleavage.

\section{INTRODUCTION}

The modes by which bonds are cleaved during coal liquefaction continues to be a subject of controversy, not only because the nature of the "critical" linkages in coals are not known with any certainty, but also because the detailed nature of some of the hydrogen-transfer reactions that lead to cleavage is still not fully understood. It is now fairly well agreed that ipso hydrogen displacement not involving free $\mathrm{H}$-atoms can result in the cleavage of some coal-like structures under liquefaction conditions (1-8). However, it is still a matter of debate whether such cleavage is (a) general for linkages to aromatic rings, (b) significant for coal liquefaction, and (c) takes place by the radical hydrogen-transfer (RHT) process, as has been claimed (1). In this paper we present data that indicate that cleavage not involving free $\mathrm{H}$-atoms (i.e., a solvent-mediated hydrogenolysis) is general for linkages to aromatic rings (though at rates which vary widely with the nature of the ring system). We also discuss, in the light of this recent data, some previously reported results that suggest such cleavages are indeed significant in coal liquefaction. Finally, we discuss those mechanistic alternatives to an actual RHT process that have not been eliminated by previous results. We defer all discussion of RHT itself or its specific mechanistic alternatives until the questions of generality of solvent mediated hydrogenolysis and its relevance to coal liquefaction have first been considered.

\section{RESULTS AND DISCUSSION}

Cleavage of Benzylaromatics. Figure 1 shows the measured rates of ipsodisplacement of benzyl groups from arenes containing one to four aromatic rings in a 1:1 mixture of anthracene and 9,10 -dihydroanthracene at $400^{\circ} \mathrm{C}$. These experiments were performed in sealed fused-silica ampoules containing $10 \mathrm{wt} \%$ substrate in a $1: 1$ anthracene/dihydroanthracene mixture, and were analyzed by GC-MS. Displacement was observed in all cases, with the reaction becoming progressively more facile as the $\Delta \mathrm{H}^{\circ}$ for $\mathrm{H}$-atom addition to the aromatics becomes more negative. While this cleavage is indeed extremely facile for alkyl-anthracenes and -pyrenes, as has recently been noted by several authors $(4,6,7,11)$, it is clear from the data in Figure 1 that it is general for substituted aromatics, rather than unique to pyrene and anthracene type structures as has been suggested (6).

The defined first-order rate constants increase by almost four orders of magnitude (a factor of $6 \times 10^{3}$ ) in going from diphenylmethane to 1 -benzylpyrene. This sensitivity is very similar to that observed by Futamura and coworkers (7) for reaction of diarylmethanes in tetralin, and is far greater than would result from addition of highly reactive free $\mathrm{H}$-atoms to the respective arenes to give the cyclohexadienyl radical cleavage intermediates. Reported $\mathrm{H}$-atom addition rates (9) give an Evans-Polanyi factor less than 0.2 and an anticipated rate increase of less than a factor of ten for free $\mathrm{H}$-atom addition to benzylaromatics in this series. Thus, there is little doubt that some active $\mathrm{H}$-donor other than $\mathrm{H}$-atom itself is transferring hydrogen to the closed-shell reactants to generate the necessary cyclohexadienyl radical intermediate. 


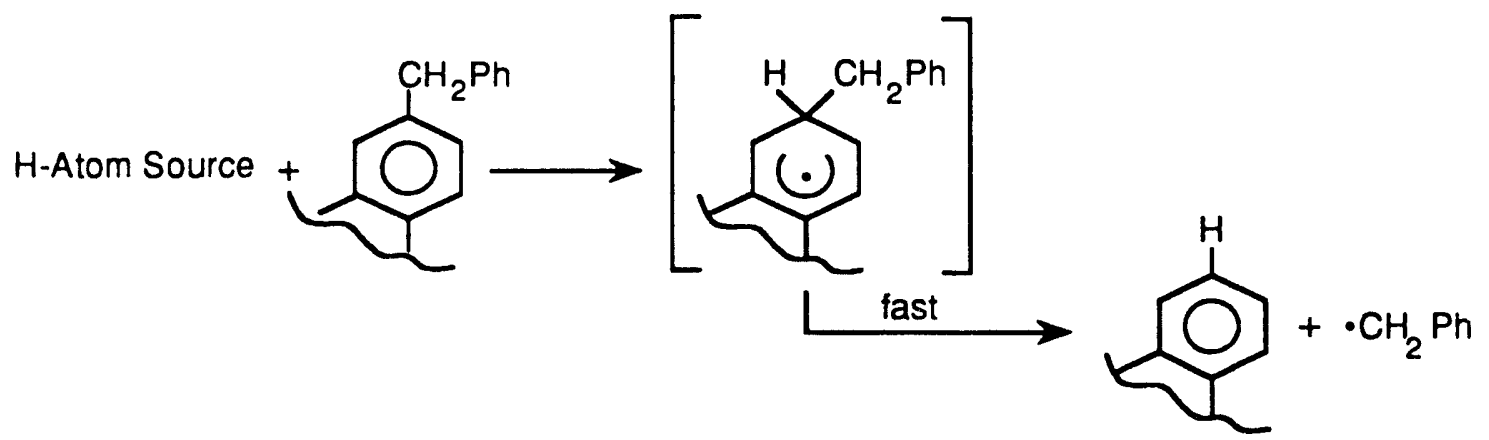

Scheme 1. Cleavage of Benzylaromatics by H-Atom Transter.

Transfer of an $\mathrm{H}$-atom directly from a dihydroaromatic (i.e., an RRD process) would certainly exhibit high selectivity (higher even than RHT). However, the rough similarity of cleavage rate constants observed in solvents having vastly different $\mathrm{C}-\mathrm{H}$ bond strengths, such as dihydroanthracene and dihydrophenanthrene $(1,2,11,22)$, and even tetralin $(7)$, have already demonstrated that RRD cannot, in all cases, constitute the stoichiometric and rate-determining $\mathrm{H}$ transfer step.

Significance for Coal Liquefaction. An explicit determination of the importance of cleavage by ipso-desubstitution in coal liquefaction, as noted above, is not possible at the present time, since the nature of the critical linkages broken during liquefaction cannot be determined with any certainty. However, as we have previously pointed out, (a) the ability of hydroaromatics to engender hydrogenolysis even in the absence of hydrogen pressures and catalysts, (b) the effectiveness of these known hydrogenolysis agents in coal liquefaction, and (c) the ineffectiveness of pure "scavengers", such as toluene, ethylbenzene and indane, together strongly suggest that hydrogenolytic cleavage of strong bonds is important in coal liquefaction $(1,11,12-15)$. In addition to this descriptive evidence, we have shown several instances where the incorporation of strong-bond cleavage into the liquefaction mechanism pictures enables one to rationalize, and in some cases (15) even predict, coal liquefaction behavior that defies interpretation if one is limited to the traditional weak-bond scission picture of liquefaction. Studies by Zabransky and Stock (16) on coals with various structures grafted onto them very clearly showed that scission of strong bonds induced by the system was competitive with scission of the weak bonds.

The importance of hydrodealkylation has been questioned on the grounds that it is generally a very slow reaction and that other reactions, most notably $\mathrm{H}$-abstraction-- $\beta$-scission, can also result in cleavage of strong bonds. Recently, Ceylan and Stock (17) have reported that demethylation of 1,3-dimethylnaphthalene in tetralin/coal mixtures occurs only to a minor extent $(\sim 1-4 \%)$ in two hours at $400^{\circ} \mathrm{C}$, and is much slower than the H-abstraction-- $\beta$-scission cleavage of 1,3-diphenylpropane $\left(-35 \%\right.$ at $400^{\circ} \mathrm{C}$ in $30 \mathrm{~min}$.). We do not disagree with these results. Indeed, we find the rates reported by Ceylan and Stock for demethylation of 1,3-dinaphthylmethane to be in good agreement with those we had reported for the decomposition of 1,2'-dinaphthylmethane $(1,12)$.

However, in trying to judge whether hyhdrodealkylation is a significant bond cleavage mode in liquefaction, we must remember that the $\mathrm{H}$-abstraction-- $\beta$-scission chain decomposition cannot be the critical bond cleavages that occur during coal liquefaction. H-abstraction-- $\beta$ scission cleavages are recognized (5) to be very facile at $400^{\circ} \mathrm{C}$, even under neat conditions, and are known not to benefit significantly from tetralin or other hydrogen donors. This type of bond cleavage makes the aliphatic portions of crude petroleums easy to thermally crack even in the absence of H-donors, but it does not lead to substantially increased distillate production rates in the presence of donors or other added sources of hydrogen $(18,19)$. This behavior is of course in stark contrast to that of coals, whose liquefaction benefits enormously from "donor" solvents. Thus, while bond cleavages of the H-abstraction-- $\beta$-scission type may indeed be more facile than the typical hydrodealkylation reaction, they are not necessarily the important category of cleavage. By the very fact that ispo desubstitutions sometimes occur only at modest rates and primarily in the presence of favorable reagents, they might properly be judged to be more "critical" than those cleavages which are more facile, and occur anyway. 
Furthermore, the rates of hydrodealkylation reactions are highly dependent on the nature of the aromatic ring system to which the linkage is connected, as shown in Figure 1. In addition to the effect of ring size, illustrated by the data in Figure 1, there are the steric and electronic effects of other substituents, notably alkyl and hydroxyl groups. In previous work involving hydroquinonepromoted dealkylation (20), we had observed that in dihydroanthracene the demethylation of 2methyl-1-naphthol is $~ 10$ times faster than that of 2-methylnaphthalene. Given the degree of phenolic substitution on aromatic ring systems in bituminous and lower rank coals, the cleavage of alkyl linkages to any given naphthalene ring system in a coal is very likely to be significantly higher than that of methylnaphthalene. For instance, had Ceylan and Stock used a methylnaphthol as their probe molecule, we anticipate they would have observed 20 to $30 \%$ demethylation in two hours at $400^{\circ} \mathrm{C}$ in their tetralin-coal-resid mixtures.

Finally, the cleavage rates for low molecular-weight model compounds are not necessarily indicative of how that same bond type will behave in a polymeric matrix such as coal. We have recently described (13) the "liquefaction" of a bibenzyl-type polymer, poly (1,4dimethylenenaphthalene), in which the bund scission by hydrodealkylation was observed to be much faster than we had anticipated on the basis of monomeric model compound measurements. Furthermore, the net rate of spontaneous scission (homolysis) of the weak central bond was found to be much slower than one would anticipate from non-polymeric model compound measurements. We rationalized this latter observation by suggesting that the polymeric matrix provides an effective cage in which recombination of spontaneously produced benzylic radicals is drastically reduced. In contrast, bond scission by hydrodealkylation is a process not so easily reversed (since reversal involves an activated radical addition process to produce a highly unstable cyclohexadienyl radical). In fact, it appears that strong bond scission is enhanced in the polymeric system. Most likely, this is because every act of scavenging of polymer fragments by the donor dihydrophenanthrene produces a 9-hydrophenanthryl radical, which is capable of engendering hydrodealkylation, in the vicinity of the polymer. Regardless of the correctmess of these explanations, the experimental result was that a hydrodealkylation expected to be some 300 times slower than a weak-bond homolysis had become, in the polymeric system, roughly as fast (13).

For all of the reasons cited in the above paragraphs, we assert that the fact that nonpolymeric, unhydroxylated, two-ring probe molecules cleave at the rate of only a few percent per hour does not constitute convincing evidence that cleavages by ipso-substitution are unimportant in coal liquefaction. On the contrary, the other evidence retierated above warrants the acceptance, at least as a working hypothesis, of the proposition that ipso-diplacement by hydrogen constitutes an important part of coal conversion under liquefaction and coprocessing conditions. Given this conclusion, it becomes more than a mere academic exercise to determine in greater detail how the hydrogen transfer which induces this cleavage is taking place.

The Mechanism of Solvent-Mediated Hydrogenolysis. In the purely radical realm, several pathways for transfer of hydrogen leading to strong-bond cleavage have been considered $(1,2,4,6,21,22)$. These pathways include radical hydrogen-transfer (RHT), reverse radical-disproportionation (RRD), also called "molecule-induced homolysis," concerted transfer of $\mathrm{H}_{2}$, and a multi-step process in which the hydrogen atom source is the same cyclohexadienyl radical carrier species that would be the hydrogen atom donor in RHT itself. Another alternative that cannot be categorically excluded is an electron-transfer--proton-transfer sequence. Although we have been unable to find definitive evidence that would rule out this possibility, we consider it unlikely in systems where both the donor and acceptor are hydrocarbons.

Reverse radical-disproportionation has in some cases (i.e., those with 9,10dihydroanthracene as the donor and high concentrations of substituted anthracenes as the acceptor) been shown (22) to constitute the stoichiometric hydrogen-transfer step, but with other common donor components, such as 9,10-dihydrophenanthrene and 4,5-dihydropyrene, RRD has been shown $(1,2)$ not to be a major contributor. Similarly, thermodynamic requirements make a concerted transfer of $\mathrm{H}_{2}$ much slower than sequential transfer in most cases of interest here $(1,23)$. We have also previously presented evidence that a three-step indirect transfer process, such as that depicted in Scheme 2, is not responsible for the observed cleavage (1). However, recent experiments and calculations $(6,8)$ have also raised additional questions (at least in the experimentally and computationally accessible systems) about the specific direct transfer route we 
had previously invoked (RHT). Therefore, in the paragraphs below, we reexamine the principal remaining possibility, namely the indirect route.

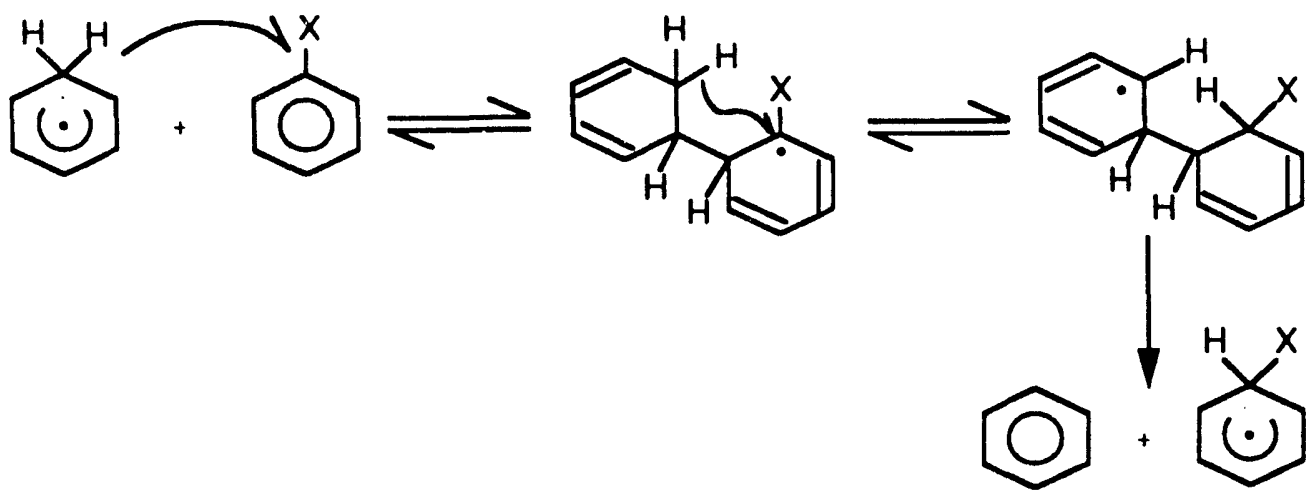

Scheme 2. Three-Step H-Transfer Mechanism

H-transfer by a Multi-Step Process. This route is comprised of three known elementary reactions: radical addition, intramolecular $\mathrm{H}$-atom abstraction, and $\beta$-scission.

Because this was a reasonable alternative to the invoking of a new reaction in RHT, and because it had been previously suggested as a likely alternative (21), we discussed this possibility in detail in an earlier paper (1). At that time we ruled it out on the basis of two principal considerations. First, ipso $\mathrm{H}$-transfer by an indirect route requires initial radical-addition at some position other than ipso, usually ortho or para to the ipso position, depending on whether the donor radical is of the 9hydrophenanthryl type or the 9-hydroanthryl type. In some cases this addition would be extremely electronically unfavorable, because ortho or para is a fused ring position. Second, because reversal of the initial addition is expected to be many orders of magnitude faster than intramolecular $\mathrm{H}$-abstraction (1), we would anticipate many initial additions to different sites (i.e., not just those o- or p- to the substituent), including ipso attack. Ipso attack should then lead to radical displacement products, which were often not observed. Since the recent experimental and theoretical work of Autrey and Franz (8), and of Freund et al.(6), have raised additional questions about the viabilitiy of the RHT pathway itself, we felt it was desirable to provide additional experimental evidence on the matter.

The most convincing evidence against the indirect route comes in fact from the displacement of 1-substituted pyrene derivatives -- ironically the same system whose reactions have caused Freund et al. (6) to invoke the indirect route. A feature of all indirect routes that commence with a radical addition is that subsequent intramolecular $\mathrm{H}$-abstraction provides a set of linked aromatic systems in which the original donor framework again bears the free radical and the substrate portion has become a dihydro derivative. In other words, transfer of a single $\mathrm{H}$-atom requires formation, as an intermediate, of a dihydro species. In the case of ultimate transfer of a hydrogen to the 1-position of pyrene, this intermediate would be a 1,2-or a 1,5-dihydropyrene. Both of these species are highly unstable (relative to the 4,5-dihydro species), since their formation requires destruction of the aromaticity of two of the rings of pyrene. Although there are no measured heats of formation available for these unstable dihydropyrenes, we can reliably estimate that the required intramolecular $\mathrm{H}$-abstraction reactions would be more than three orders of magnitude slower for reaction of pyrene derivatives than for reaction of naphthalene derivatives (Table 1).

In contrast with these estimates, experimental results show that cleavage of pyrene derivatives is actually about two orders of magnitude faster than that of naphthalene derivatives. There is now not merely a quantitative mismatch between estimated and observed relative rates, but a qualitative inconsistency: those reactions which would have to be much slower, are actually much faster. Thus the increased susceptibility of pyrene linkages to ipso displacement that has been recently discussed $(4,6)$ cannot be the result of a multi-step sequence of free radical reactions that has the same net result as the one-step RHT process. 


\section{CONCLUSIONS}

The experimental evidence now makes it clear that cleavage induced by $\mathrm{H}$-transfer is general for benzyl and alkyl linkages to aromatic ring systems. The substrate and positional selectivities of this cleavage show that it cannot simply result from displacement by free $\mathrm{H}$-atoms, and relative rates in different solvent systems show it cannot result merely from reverse radicaldisproportionation. Comparison of the response of coal liquefaction on the one hand and $\mathrm{H}$ abstraction-- $\beta$-scission on the other to the presence of donor solvents is a strong indicator that the latter type of strong-bond cleavage, while probably important in resid conversion, does not constitute the "critical" cleavage that distinguishes between better and poorer liquefaction systems. Finally, a multi-step radical process for hydrogen transfer is ruled out by the sensitivity of linkages to the 1-position of pyrene, coupled with the marked instability of the 1,2- and 1,5-dihydropyrene intermediates that would be necessary in a multi-step process.

\section{REFERENCES}

1. McMillen, D. F.; Malhotra, R.; Chang, S. -J.; Fleming, R. H.; Ogier, W. C.; Nigenda, S. E. Fuel $1987,66,1611$.

2. Bilmers, R.; Brown, R. L.; Stein, S. E. Int. J. Chem. Kinetics 1989, 21, 375.

3. Bockrath, B. C.; Schroeder, K. T.; Smith, M. R. Energy and Fuels 1989, 3, 268.

4. Smith, C. M.; Savage, P. E., "Reactions of Polycyclic Alkylaromatics, Part 1: Pathways, Kinetics, and Mechanisms for 1-Dodecylpyrene," Ind. Eng. Chem. Res. 1991, 31, XXX.

5. Poutsma, M. L. Energy and Fuels, 1990, 4, 114.

6. Freund, H.; Matturro, M. G.; Olmstead, W. N.; Reynolds, R. P.; Upton, T. H. Am. Chem. Soc., Div. Fuel Chem. Preprints 1990, 35(2), 496.

7. Futamura, S.; Koyanagi, S.; Kamiya, Y. Fuel 1988, 67, 1436

8. Autrey, T.; Franz, J. A. Am. Chem. Soc., Div. Fuel Chem. Preprints 1990, 35(2), 382

9. a. Tsang, W. J. Amer. Chem. Soc. 1985, 107, 2872.

b. Tsang, W. J. Phys. Chem. 1986, 90, 1152.

10. Bockrath, B. C.; Bittner, E.; McGrew, J. J. Am. Chem. Soc. 1984, 106, 135.

11. Malhotra, R.; McMillen, D. F. Energy and Fuels 1990, 4, 184.

12. McMillen, D. F.; Malhotra, R.; Hum, G. P.; Chang, S. -J. Energy and Fuels 1987, 1, 193.

13. Malhotra, R.; McMillen, D. F.; Tse, D. S.; St.John, G. A. Am. Chem. Soc. 1989, 3, 465.

14. McMillen, D. F.; Malhotra, R.; Nigenda, S. E. Fuel 1989, 68, 380.

15. McMillen, D. F.; Malhotra, R.; Tse, D. S., Energy and Fuels 1991, 5, XXX.

16. Rose, G. R.; Zabransky, R. F.; Stock, L. M.; Huang, C.-B.; Srinivas, V. R.; Tse, K.-T. Fuel 1984, 63, 1339.

17. Ceylan, K.; Stock, L. M. Fuel 1990, 69, 1386. 
18. Savage, P. E.; Klein, M. T.; Kukes, S. G. Energy and Fuels 1988, 2, 619.

19. Khorasheh, F.; Rangwala, H. A.; Gray, M. G.; Lana, I. G. D. Energy and Fuels 1989, 3, 716.

20. McMillen, D. F.; Chang, S. -J.; Fleming, R. H.; Laine, R. M.; Malhotra, R.; Nigenda, E.; Ogier, W., "Effect of of Amine Solvents and Oxygen Functionalities on Coal Liquefaction," EPRI Research Project 2147-5, 1985.

21. Stein, S. E, "Free Radicals in Coal Conversion," in Chemistry of Coal Conversion, Schlosberg, R. H., Ed.; Plenum Press: N.Y., 1985, 13.

22. Billmers, R.; Griffith, L. L.; Stein, S. E., J. Phys. Chem. 1986, 90, 517.

22. King, H.-H.; Stock, i.. M. Fuel 1981, 60, 748.

23. Benson, S. W., Therochemical Kinetics, 2nd ed; John Wiley and Sons: New York, 1976.

24. Pedley, J. B.; Naylor, R. D.; Kirby, S. P., Thermodynamics of Organic Compounds, Chapman and Hall: New York, 1986.

TABLE 1.

Comparison of Measured Rates of Cleavage with Estimated Rates of Multi-Siep Components for Naphthalene and Pyrene Derivatives.

\begin{tabular}{|l|c|c|c|c|}
\hline \multirow{2}{*}{ Benzylaromatic } & $\begin{array}{c}\text { exptl } \\
\text { kcleavage, } \mathrm{s}^{-1}\end{array}$ & \multicolumn{2}{|c|}{$\begin{array}{c}\text { Estimated Rate Constants } \\
\text { Reaction of } \\
\text { Three-Step Intermediate, } \mathrm{s}^{-1}\end{array}$} & $\begin{array}{c}\Delta \mathrm{H}^{\circ} \text { Intramol } \\
\mathrm{H}-\mathrm{Abs}^{\mathrm{b}} \\
\mathrm{kcal} / \mathrm{mol}\end{array}$ \\
\cline { 3 - 5 } & & Reversal & Intramol H-Abs & \\
\hline 1-Benzylnaphthalene & $3 \times 10^{-6}$ & $5 \times 10^{-8}$ & $6 \times 10^{-6}$ & $\sim-1$ \\
\hline 1-Benzylpyrene & $5.4 \times 10^{-4}$ & $5 \times 10^{-8}$ & $<4 \times 10^{-3}$ & $>+14$ \\
\hline
\end{tabular}

a. Rate constants estimated according to the regimen and data sources given in reference 11.

b. Estimated by group additivity procedures as described in reference 23 , and by comparison with measured heats of formation for closest available analogs, as given in reference 24 . 


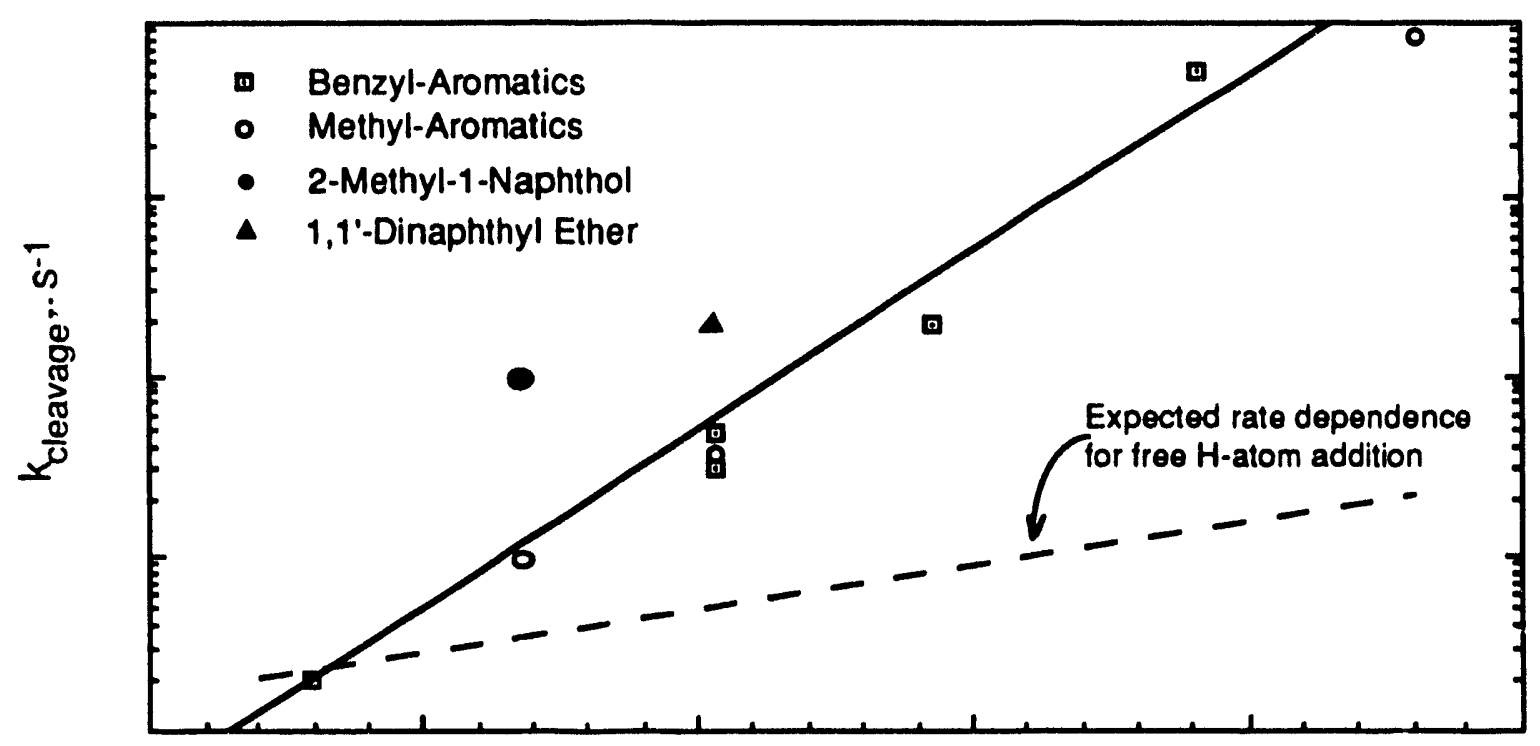

$-\Delta \mathrm{H}^{\circ}$.(H-Atom Addition), $\mathrm{kcal} / \mathrm{mol}$ का

Figure 1 Measured rates of cleavage of benzyl-and methyl- aromatics in anthracene/ dihydroanthracene at $400^{\circ} \mathrm{C}$, as a function of the exothermicity of free $\mathrm{H}$-atom addition.

Measured and estimated $\Delta H^{\circ}$ (addition) are taken from reference 11. They are, in $\mathrm{kcal} / \mathrm{mol}$ : phenyl, -22 ; 2-naphthyl, -26; 1-naphthyl, -27.9; 9-phenanthryl, -33.8; 1-pyrenyl, -38.9; and 9-anthryl, -43. 

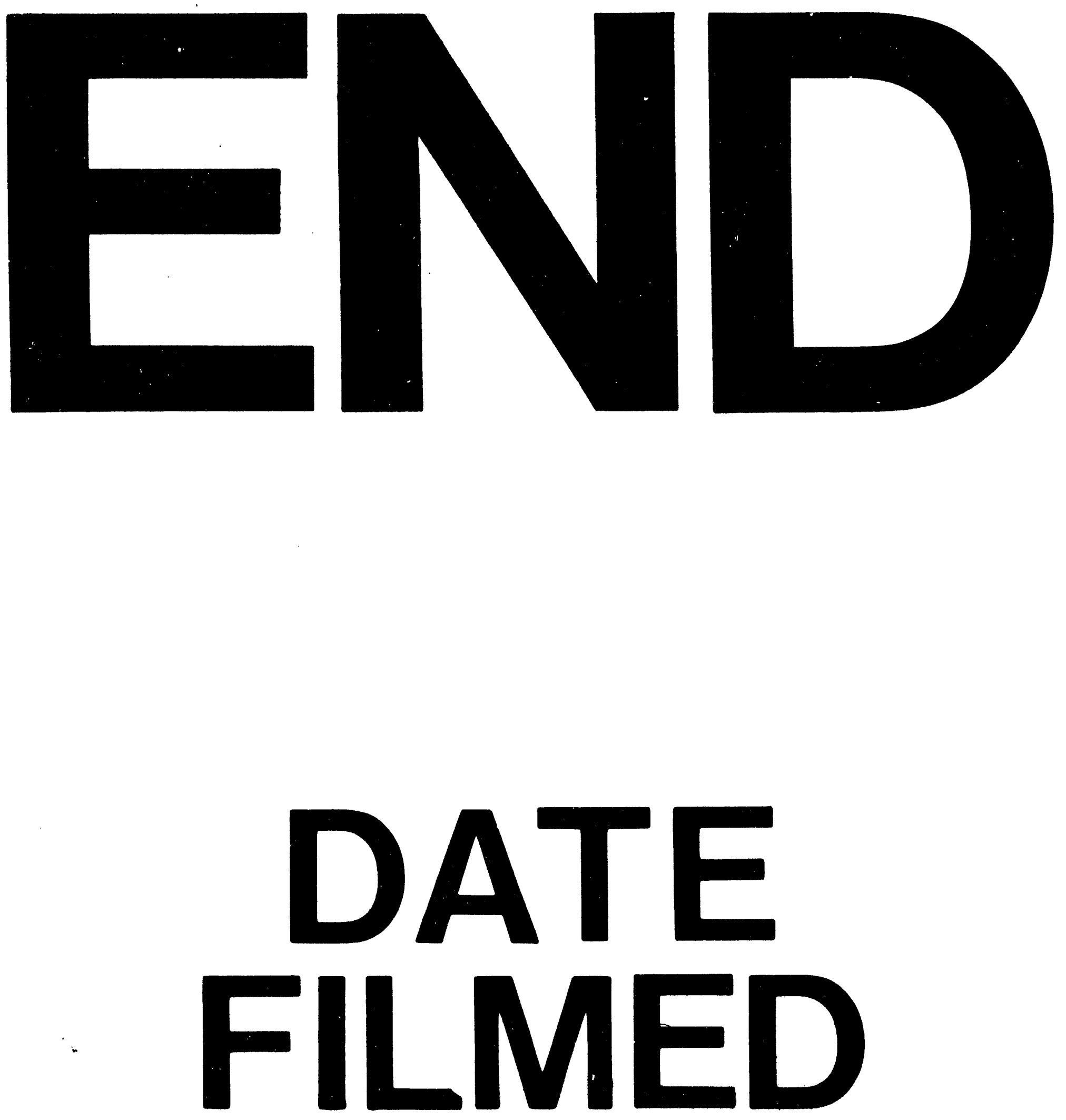

1

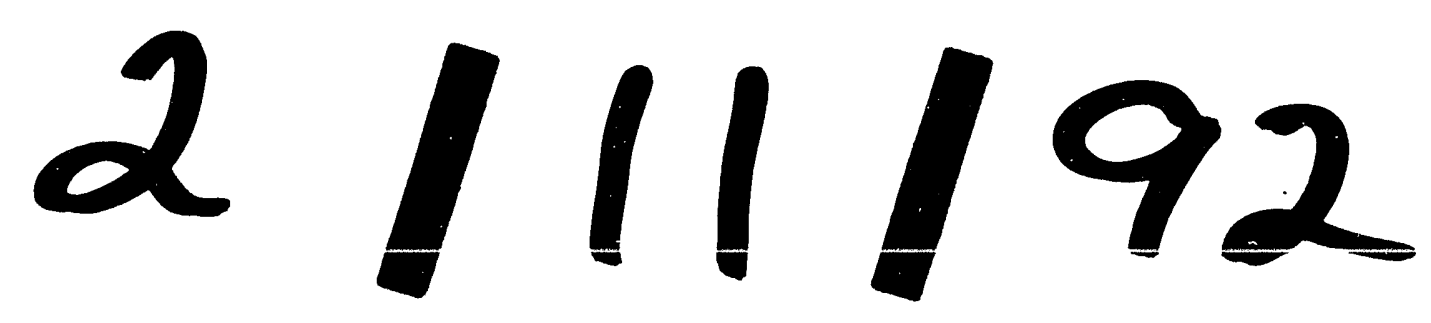


